Research Article

\title{
Experimental Study on the Influence Factors of Flow Velocity Structure and Turbulent Characteristics in Open Channel with Biomimetic Grass
}

\author{
Changjing Fu, ${ }^{1,2}$ Jinguo Wang, ${ }^{1}$ Tianlong Zhao ${ }^{(D)},{ }^{1}$ and Yi Lv ${ }^{1}$ \\ ${ }^{1}$ National Engineering Research Center for Inland Waterway Regulation, Chongqing Jiaotong University, \\ Chongqing 400074, China \\ ${ }^{2}$ School of Earth Sciences and Engineering, Hohai University, Nanjing 210098, China
}

Correspondence should be addressed to Tianlong Zhao; neo_3303@163.com

Received 11 January 2021; Revised 19 July 2021; Accepted 11 August 2021; Published 24 September 2021

Academic Editor: Meng Gao

Copyright (C) 2021 Changjing Fu et al. This is an open access article distributed under the Creative Commons Attribution License, which permits unrestricted use, distribution, and reproduction in any medium, provided the original work is properly cited.

The problem of suspension treatment of subsea oil-gas pipelines has been highly concerned by engineering construction units and researchers. The current research indicates that the bionic sea grass can effectively reduce the flow rate, promote sediment deposition, and control the development of the pipeline suspension area. The velocity distribution of open channel flow with bionic grass is very complex. The height and laying space of bionic grass will affect the flow velocity distribution. At present, the flow velocity in open channels with bionic grass is mainly studied by measuring the velocity variation at the front, middle, and back of bionic grass. Few effective measurements are made for the full velocity field. The velocity field distribution of bionic aquatic grass along the vertical plane is measured by using standard particle image velocimetry (PIV). The effects of height and laying space of bionic grass on probability density distribution, spatial correlation of pulsating velocity, turbulence intensity, Reynolds stress and turbulent kinetic energy in the open channel after the protection section of bionic grass are further analyzed.

\section{Introduction}

Bionic grass is processed by a new type of polymer material that is resistant to seawater immersion and long-term erosion [1]. Domestic and foreign research shows that bionic grass can effectively reduce the flow velocity, promote sediment deposition, and will not produce secondary environmental pollution [2]. At present, there are few results on the physical model tests of bionic grass, which mainly discusses the variation of velocity at different locations and the change of sediment deposition in the protective section of bionic grass [3]. Presently, studies about the full-field velocity of the open channel flow behind the bionic grass protection section are very few; especially, the turbulence characteristics of the flow behind the bionic grass protection section have not been reported. López et al. [4] measured the flow field with rigid plants by ADV and considered that the turbulent exchange of flow is strong at the junction of the plant layer and nonplant layer. Wilson et al. [5] analyzed and compared the effects of leafy and leafless plants on flow turbulence characteristics and found that the maximum Reynolds stress and turbulence intensity of leafy plants appeared in a higher position. Wu et al. $[6,7]$ measured the flow velocity field with rigid and flexible plants by PIV. The analysis found that the turbulence intensity of rigid plants was higher than that of flexible plants. Wang and Wang [8] considered the ecological function of plants and measured and studied the turbulence characteristics of submerged and emergent plants through flume experiments. The results show that the turbulence intensity and Reynolds stress of open channel flow containing submerged plants and emergent plants have obvious anisotropy, and at the junction of the canopy of submerged plants and the branches and leaves of submerged plants, the turbulence intensity and Reynolds stress show the maximum. Wenxin et al. [9] carried out an experimental study on the open channel flow 
of flexible submerged vegetation and found that the Reynolds stress increases linearly along the water depth in the upper layer of vegetation, while the distribution in the vegetation layer is more complex. Song et al. [10] measured the disturbance characteristics of aquatic rigid submerged vegetation and found that the density and arrangement of vegetation have obvious influence on the turbulence intensity. In this paper, the effects of the height and laying density of bionic grass on the flow structure and turbulence characteristics in the open channel behind the protective section of bionic grass are quantitatively analyzed by using the experimental data.

\section{General Situation of a Test}

A physical model test is carried out in a high precision variable slope flume in this paper. The trough is $12.6 \mathrm{~m}$ long, $0.25 \mathrm{~m}$ wide, and $0.25 \mathrm{~m}$ high. In order to reduce the influence of flume sidewall joint on flow structure, the side and bottom of the flume are composed of $3.6 \mathrm{~m}$ long glass plate, glass installation error is less than $\pm 0.2 \mathrm{~mm}$, the structural deformation of the flume is less than $\pm 0.3 \mathrm{~mm}$. A rectifier grille is placed at the entrance of the sink and a hinged tail door is arranged at the exit. The flume is equipped with an automatic water level and flow control system. The ultrasonic water level meter is used to measure the test water depth. The electromagnetic flowmeter is used to measure the test flow. The instantaneous flow velocity is measured at a distance of about $0.1 \mathrm{~m}$ from the end section of the bionic straw mat, and the distance is $0.08 \mathrm{~m}$, as shown in Figure 1.

A two-dimensional high-frequency PIV system is used to collect the flow field along the longitudinal axis of the water tank between two rows of particles in the tests. The system is mainly composed of a high-frequency CMOS camera, an $8 \mathrm{~W}$ semiconductor CW laser and PIV flow field calculation software. The pixel of CMOS camera is $2560 \times 1920$, and the maximum frame rate is $800 \mathrm{~Hz}$. The laser beam is transformed into $45^{\circ}$ sheet light by prism, and the thickness is about $1 \mathrm{~mm}$. The sheet light source enters the light from the glass bottom plate of the water tank and can penetrate the glass beads on the bed surface. WIDIM multigrid iterative image deformation algorithm is used to calculate PIV flow field, and the minimum diagnostic window is $16 \times 16$ pixels. The final resolution of the flow field is $8 \times 8$ pixels. The average time interval between two instantaneous flow fields is $1 \mathrm{~s}$ (the time interval between two images corresponding to the same instantaneous flow field is $1.25 \mathrm{~ms}$ ), and the sample capacity of each working condition is 5000 times (10000 flow field images).

Experimental flow is a constant flow. The normal model is used in testing. The flow velocity in the model is determined according to gravity similarity criterion. The test scale is $1 / 20$. The bionic grass engineering sample of T25-type is used in the test. The actual size of bionic straw mattress is $5 \mathrm{~m} \times 5 \mathrm{~m}$, the spacing between each row of bionic grass in straw mattress was $1.67 \mathrm{~m}$, and grass is $1.5 \mathrm{~m}$ high. In order to analyze the influence on height and laying distance of grass on flow velocity structure, samples of different grass heights and laying spaces are set up in this experiment. Three groups of parallel tests are carried out in each working condition. The test condition parameters are shown in Table 1.

\section{Analysis of Experimental Results}

3.1. Regularity of Lodging Regularity of Bionic Grass under Water Flow. Figure 2 shows the lodging of bionic grass under different experimental conditions. It can be seen from the figure that the denser the arrangement of bionic grass is, the more it falls. The lodging height of the T25 bionic straw mat mattress under different conditions is measured, and the results are shown in Table 2 . It can be seen that the lodging value of bionic grass increases with the increase of height and laying distance of grass. Bionic grass can form a cover layer on the riverbed by reducing the lodging height to reduce the erosion of water to the riverbed.

3.2. Velocity Distribution at Longitudinal Time-Average Velocity after the Protective Section of Bionic Grass. It is found from Figure 3 that the vertical distribution of the longitudinal velocity behind the bionic grass section with different grass height and laying spacing is different under the same flow conditions. The laying space has a great influence on the longitudinal velocity of the flow behind the bionic grass section. In order to analyze the vertical distribution of flow velocity under different conditions, the section with the maximum velocity change $x=2 \mathrm{~cm}$ is selected. It can be seen from Figure 4 that when the average velocity of cross section is small, the longitudinal velocity is linear within $2 \mathrm{~cm}$ of the canal bottom, and the value is close to zero. When the average velocity of cross section is above $2 \mathrm{~cm}$, the vertical distribution of longitudinal velocity is S-shaped. With the increase of cross section average velocity, the longitudinal velocity of the flow within $2 \mathrm{~cm}$ of the canal bottom behind the bionic grass section is parabolic distribution along the water depth. The vertical distribution of the longitudinal velocity is similar to $S$-shape at $2 \mathrm{~cm}$ above the canal bottom. The maximum longitudinal time-average velocity on the vertical is obtained at $y=5.4 \mathrm{~cm}, y=4.9 \mathrm{~cm}$, and $y=3 \mathrm{~cm}$, and the maximum values are $0.235 \mathrm{~m} / \mathrm{s}, 0.30 \mathrm{~m} / \mathrm{s}$, and $0.24 \mathrm{~m} / \mathrm{s}$, respectively. It can be seen that the maximum position of longitudinal time-average velocity on the vertical line gradually moves down with the increase of cross section average velocity, which is related to the lodging of bionic grass.

3.3. Probability Density Distribution of Fluctuating Velocity after Bionic Grass Section. In order to predict the basic characteristics of turbulent motion, the fluctuating velocity of turbulent flow in an open channel can be expressed by probability density distribution with spatial and temporal variation characteristics. The fluctuating velocity in each working condition is calculated, and the probability distribution curve of longitudinal and vertical pulsating velocity is shown in Figure 4. The “-" sign represents direction. As visible, the probability density of longitudinal fluctuating velocity in open channel flow is normal distribution after 

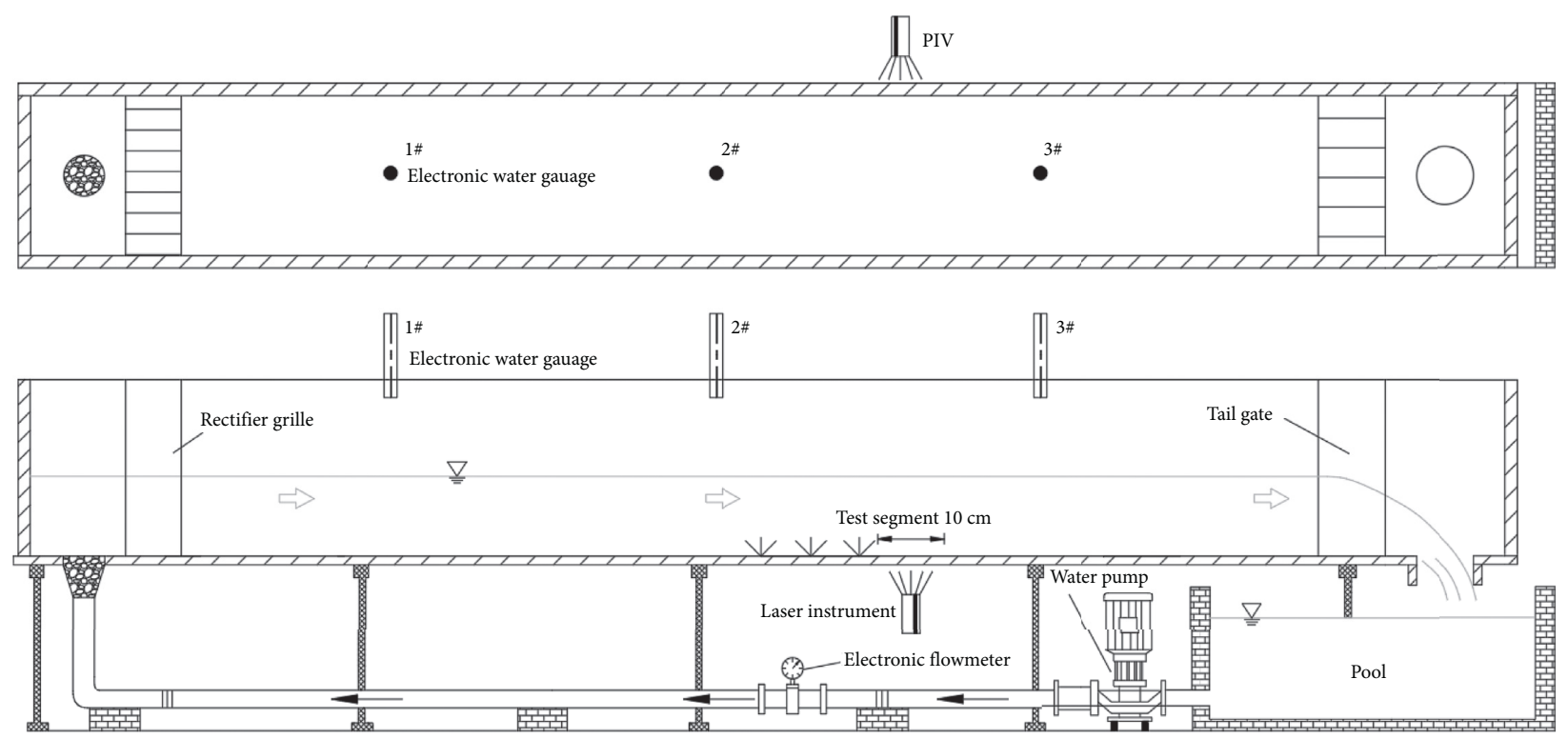

Figure 1: Schematic diagram of the flume test.

TABle 1: Test conditions and related parameters.

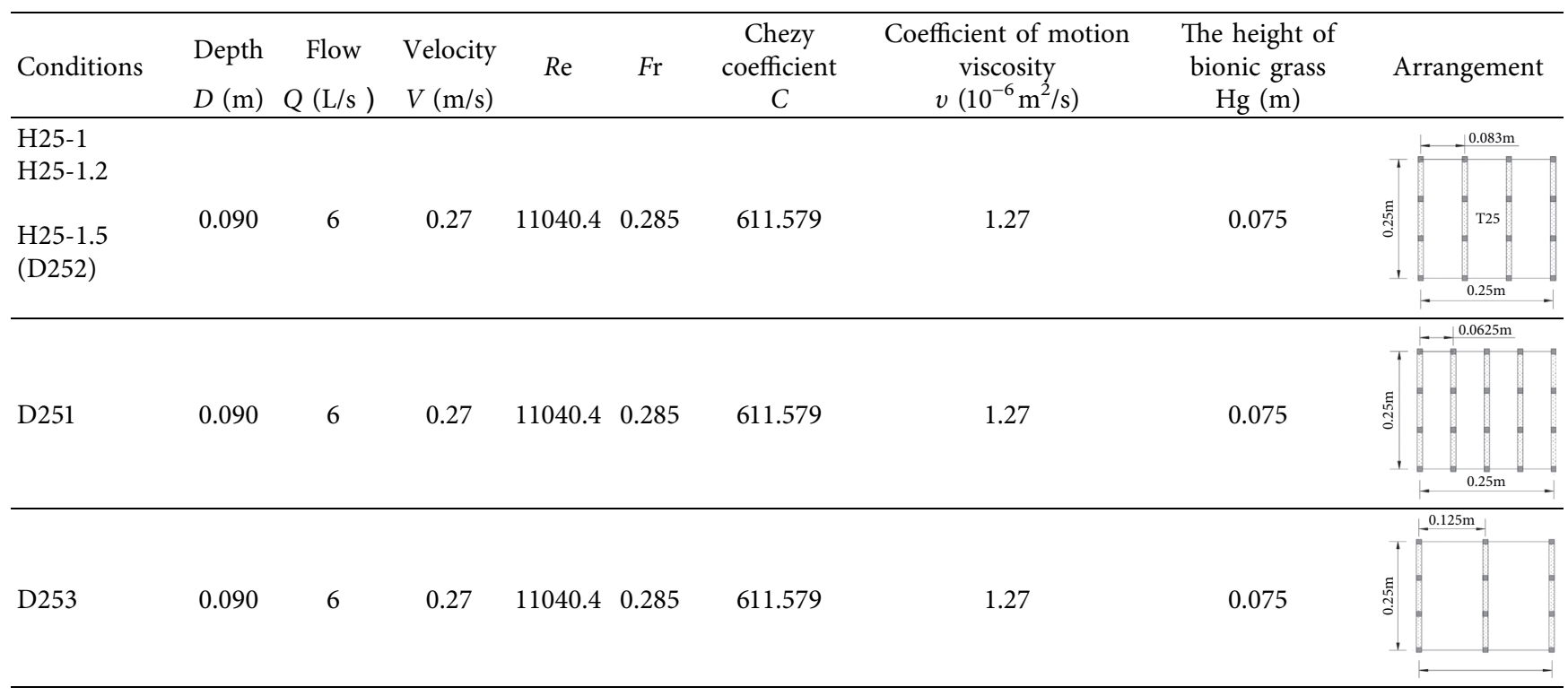

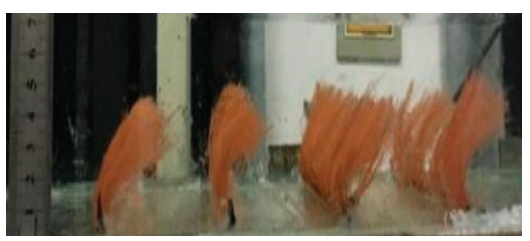

(a)

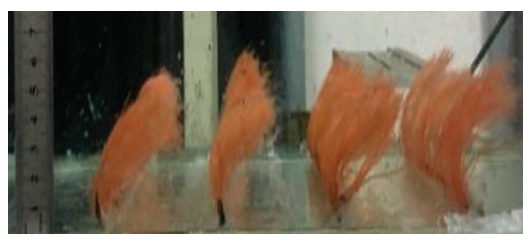

(b)

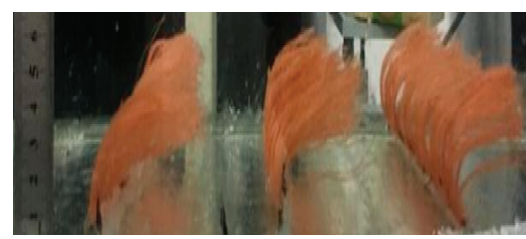

(c)

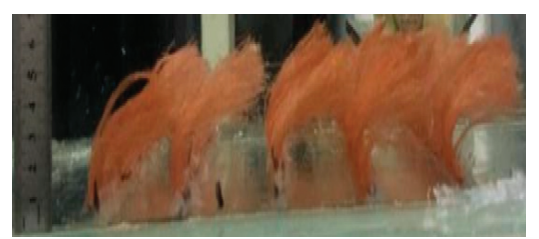

(d)

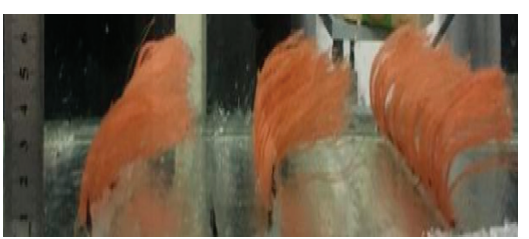

(e)

Figure 2: The lodging of bionic grass. (a) H25-1, (b) H25-1.2, (c) H25-1.5 (D252), (d) D251, and (e) D253. 
TABLE 2: Lodging value of bionic grass in conditions.

\begin{tabular}{lcc}
\hline Conditions & The original height of bionic grass $H g(\mathrm{~cm})$ & Lodging value $(\mathrm{cm})$ \\
\hline H25-1 & 5.0 & 0.4 \\
H25-1.2 & 6.0 & 0.9 \\
H25-1.5 (D252) & 7.5 & 2.0 \\
D251 & 7.5 & 1.9 \\
D253 & 7.5 & 2.2 \\
\hline
\end{tabular}

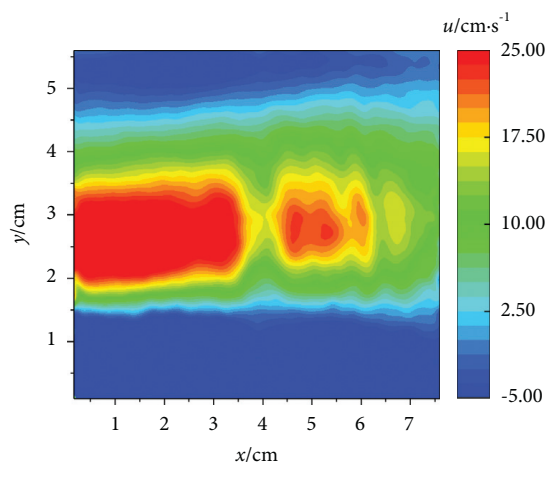

(a)

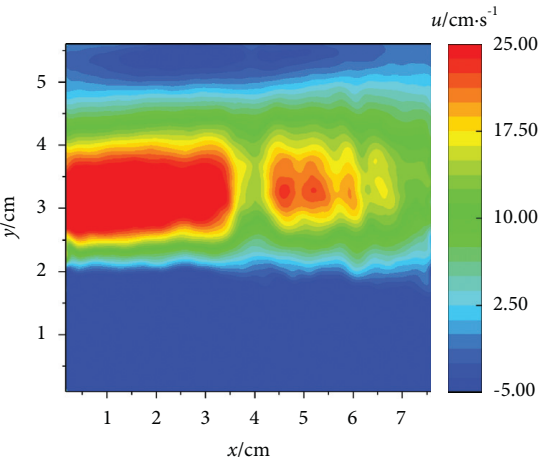

(b)

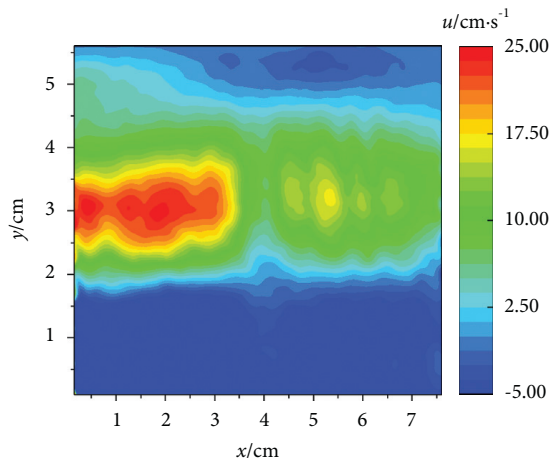

(c)

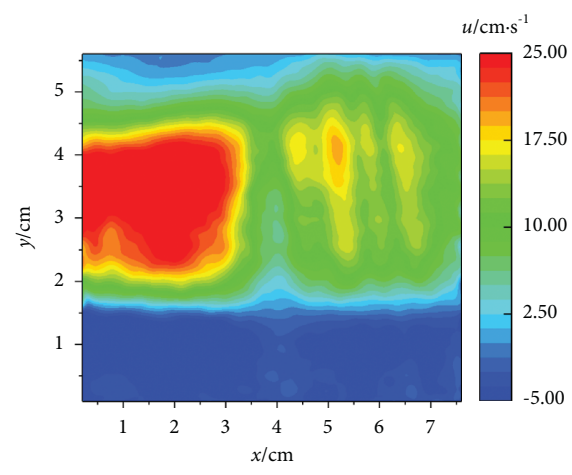

(d)

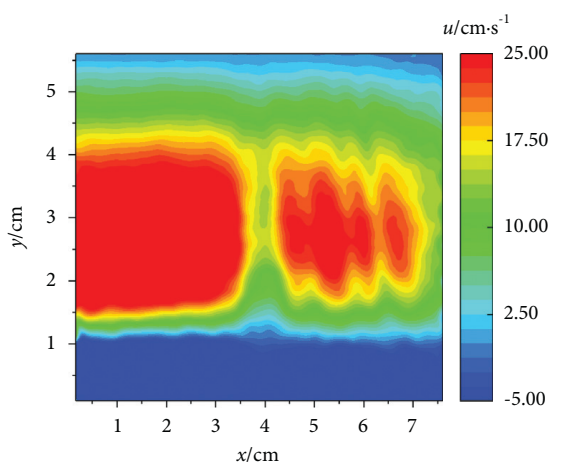

(e)

Figure 3: The distribution of the time-averaged longitudinal velocity in different working conditions. (a) H25-1, (b) H25-1.2, (c) H25-1.5 (D252), (d) D251, and (e) D253.

bionic grass protection section. Under the same flow conditions, the probability density of longitudinal pulsating velocity increases with the increase of the height of bionic grass, and the peak trend becomes steeper. However, the probability density of longitudinal pulsating velocity increases at first and then decreases with the increases of the laying distance of bionic grass, and the peak shape tends to be flat. The probability distribution of longitudinal pulsation velocity in different working conditions is shown in Figure 5.

The probability distribution of vertical fluctuating velocity in different working conditions is shown in Figure 6. It can be seen that the vertical fluctuating velocity probability density in the open channel flow behind the bionic grass protection section shows a normal distribution. Compared with the longitudinal fluctuating velocity probability density distribution, the overall peak distribution is steeper, the kurtosis of the normal distribution is larger, and the peak is sharper. Under the same flow conditions, the kurtosis of vertical pulsating velocity probability surface density distribution increases gradually with the increase of grass height and increases at first and then decreases with the decrease of bionic grass laying spacing. However, the better the symmetry of the distribution curve of vertical pulsating velocity probability, the flatter the situation of the whole peak.

\subsection{Spatial Correlation of Fluctuating Velocity after Bionic} Grass Section. The correlation coefficient is usually used to describe the spatial correlation structure of pulsating velocity quantitatively. The larger the correlation coefficient is, the better the spatial correlation of velocity is, and, on the contrary, the worse it is. The spatial correlation of pulsating velocity includes autocorrelation and cross-correlation. The calculation formulas of each correlation coefficient are as follows: 


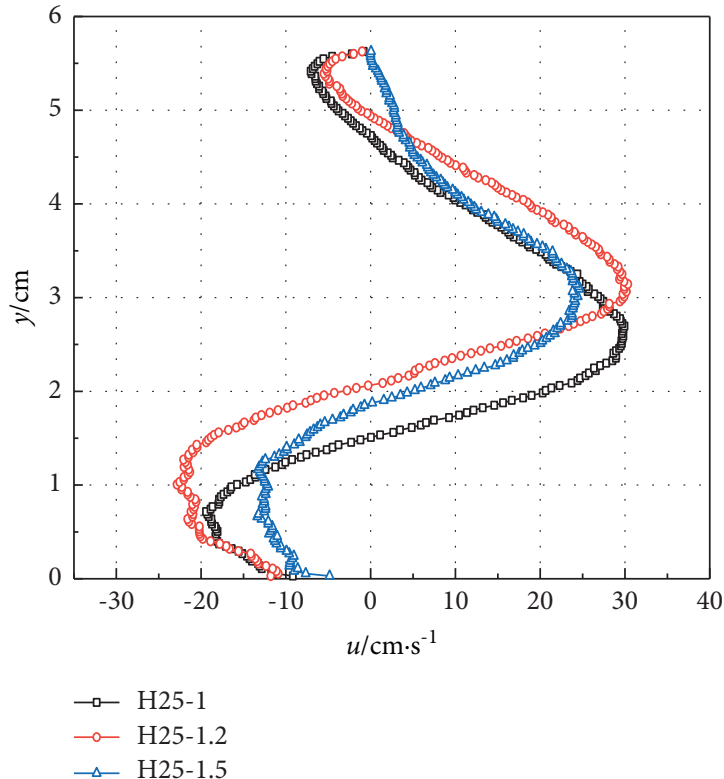

(a)

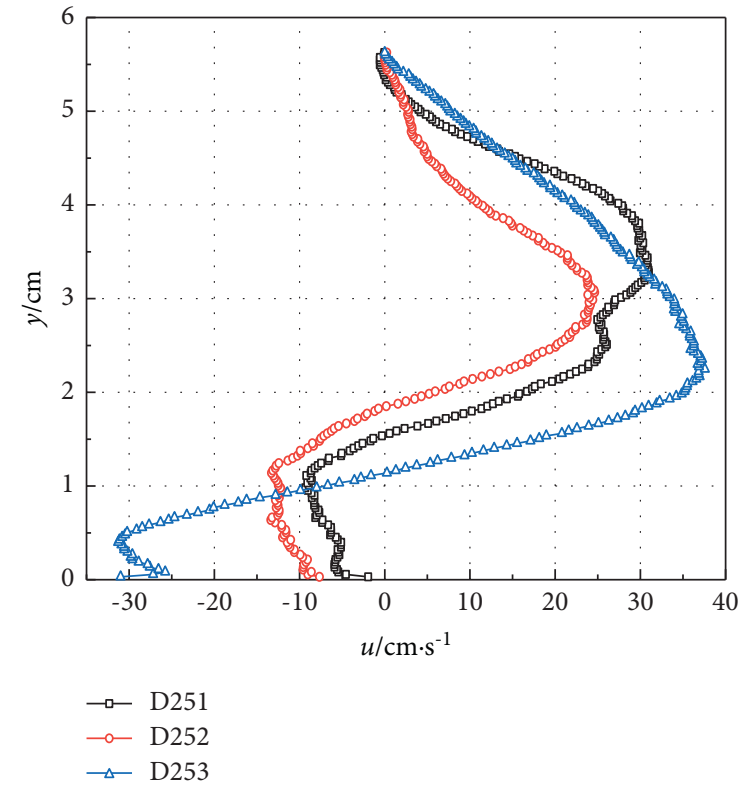

(b)

FIgURe 4: The vertical distribution of the time-averaged longitudinal velocity in different working conditions $(x=2 \mathrm{~cm})$.

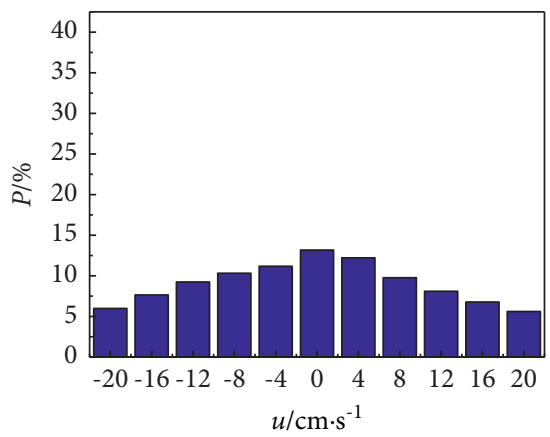

(a)

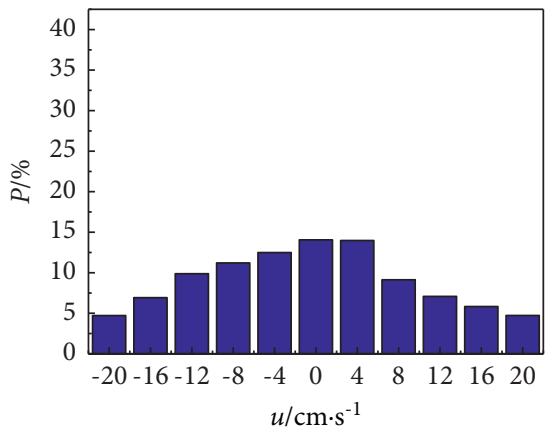

(d)

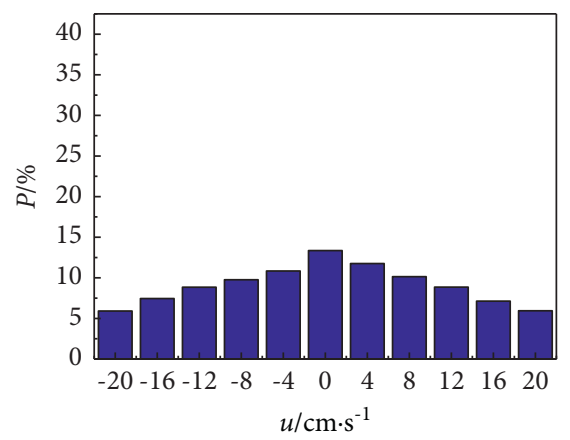

(b)

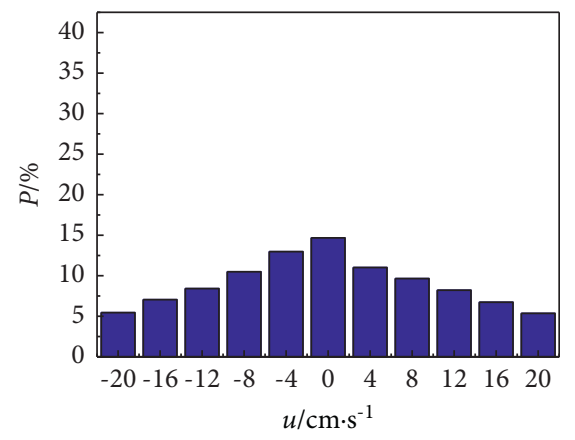

(e)

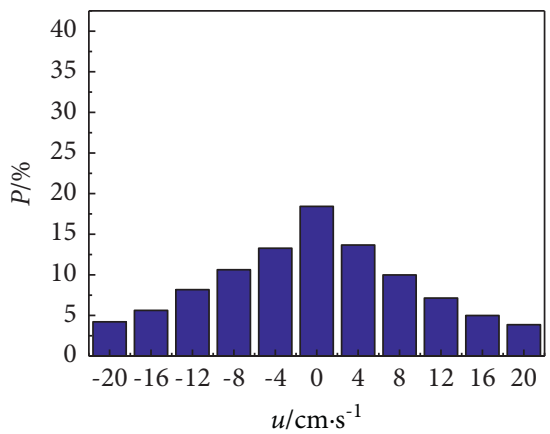

(c)

FIGURE 5: The probability distribution of longitudinal pulsation velocity in different working conditions. (a) H25-1, (b) H25-1.2, (c) H25-1.5 (D252), (d) D251, and (e) D253. 


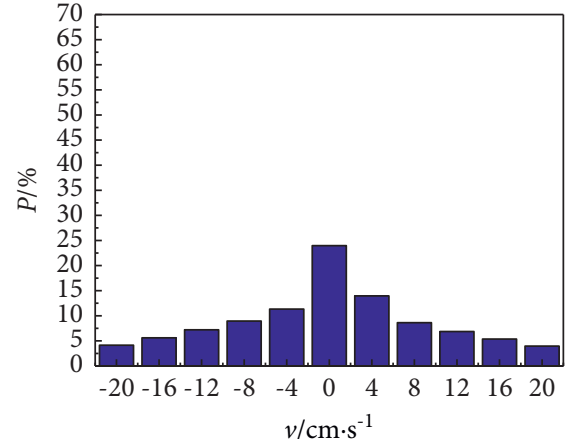

(a)

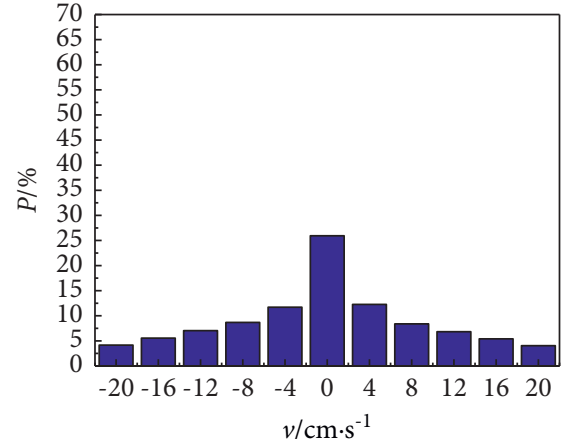

(b)

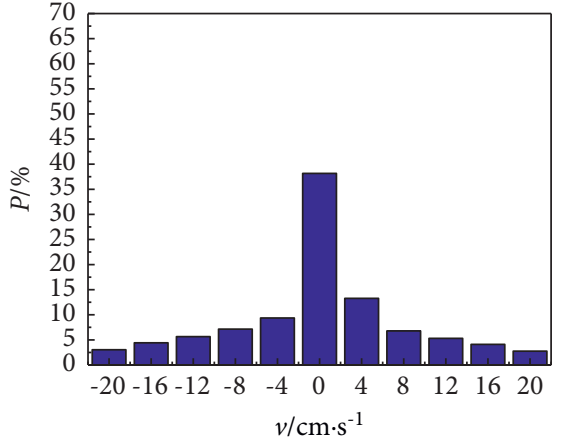

(c)

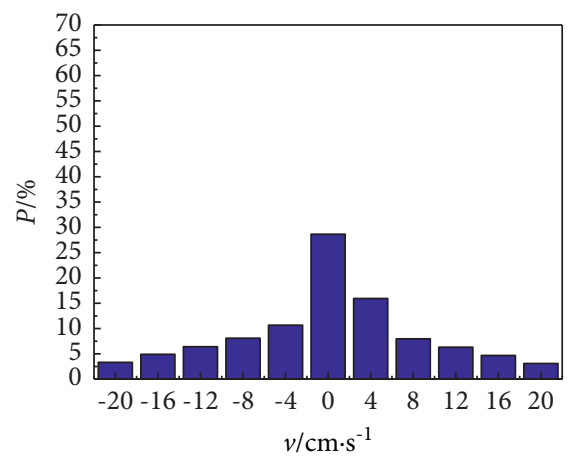

(d)

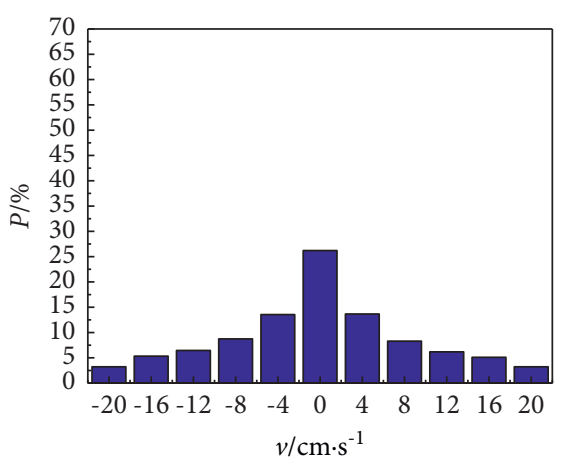

(e)

Figure 6: The probability distribution of vertical pulsation velocity in different working conditions. (a) H25-1, (b) H25-1.2, (c) H25-1.5 (D252), (d) D251, and (e) D253.

$$
\begin{aligned}
C_{u u} & =\frac{(1 / n) \sum_{i=1}^{n} u_{i}\left(x_{0}, y_{0}\right) u_{i}\left(x_{1}, y_{1}\right)}{u^{\prime}\left(x_{0}, y_{0}\right) u^{\prime}\left(x_{1}, y_{1}\right)} \\
C_{u v} & =\frac{(1 / n) \sum_{i=1}^{n} u_{i}\left(x_{0}, y_{0}\right) u_{i}\left(x_{1}, y_{1}\right)}{u^{\prime}\left(x_{0}, y_{0}\right) v^{\prime}\left(x_{1}, y_{1}\right)} \\
C_{v v} & =\frac{(1 / n) \sum_{i=1}^{n} v_{i}\left(x_{0}, y_{0}\right) u_{i}\left(x_{1}, y_{1}\right)}{v^{\prime}\left(x_{0}, y_{0}\right) v^{\prime}\left(x_{1}, y_{1}\right)} \\
C_{v u} & =\frac{(1 / n) \sum_{i=1}^{n} v_{i}\left(x_{0}, y_{0}\right) u_{i}\left(x_{1}, y_{1}\right)}{v^{\prime}\left(x_{0}, y_{0}\right) u^{\prime}\left(x_{1}, y_{1}\right)}
\end{aligned}
$$

$C_{u u}$ and $C_{v v}$ are autocorrelation coefficients, $C_{u v}$ and $C_{v u}$ are cross-correlation coefficients, $\left(x_{0}, y_{0}\right)$ and $\left(x_{1}, y_{1}\right)$ are the coordinates of any two points in the space, $n$ is the sample size, $u$ and $v$ are longitudinal pulsating velocity and vertical fluctuating velocity, $u^{\prime}=\sqrt{(1 / n) \sum_{i=1}^{n} u_{i}^{2}}$ and $v^{\prime}=\sqrt{(1 / n) \sum_{i=1}^{n} v_{i}^{2}}$ are longitudinal turbulence intensity and vertical turbulence intensity.

In this paper, the geometric center point of the flow field acquisition window is $\left(x_{0}, y_{0}\right)$, and the surrounding space point is $\left(x_{1}, y_{1}\right)$. The autocorrelation coefficients and the cross-correlation numbers are calculated. The correlation structure characteristics and variation rules of the fluctuating velocity space after the bionic grass section under the action of water flow are discussed.
3.4.1. Spatial Autocorrelation. The autocorrelation coefficient $C_{u u}$ and $C_{v v}$ cloud images of flow velocity in open channel flow after bionic grass protection section are shown in Figures 7 and 8. The result shows that $C_{u u}$ and $C_{v v}$ are positively correlated spatial structures around central point. $C_{u u}$ and $C_{v v}$ values decrease with increasing distance between analytical points and geometric center points of acquisition windows. It shows that the bigger the distance between two points, the weaker the spatial autocorrelation of pulsating velocity. The innermost circle of $C_{u u}$ and $C_{v v}$ images is roughly rounded. $C_{u u}$ and $C_{v v}$ near circle center are isotropic. With the increase of the height of bionic grass, the area of the innermost circle of cloud images of $C_{u u}$ and $C_{v v}$ increased at first and then decreased.

For further quantitative analysis of $C_{u u}$ and $C_{v v}$ cloud images distribution features, define an area coefficient of $\zeta=A_{r} / A, A_{r}$ as the area surrounded by isoline corresponding to correlation coefficient $r, A$ as total area of analytical window. Obviously, with the bigger $\zeta$, the proportion of area surrounded by isoline of correlation coefficient is larger than that of window area. $\zeta_{u u}, \zeta_{v v}, \zeta_{u v}$, and $\zeta_{v u}$ indicate area coefficients of $C_{u u}, C_{v v}, C_{u v}$, and $C_{v u}$.

The values for $\zeta_{u u}$ and $\zeta_{v v}$ in different operating conditions are shown in Table 3 . It can be seen from Table 3 that $\zeta_{u u}$ and $\zeta_{v v}$ generally increase first and then decrease with $r$ increase. The variation of area surrounded by isoline is more sensitive when $r$ is larger. When $r$ at about $0.02, \zeta_{u u}$ and $\zeta_{v v}$ values reach maximum. Under the same flow condition, 


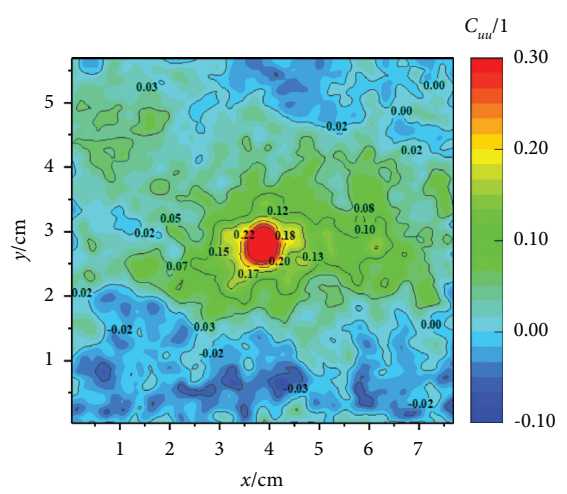

(a)

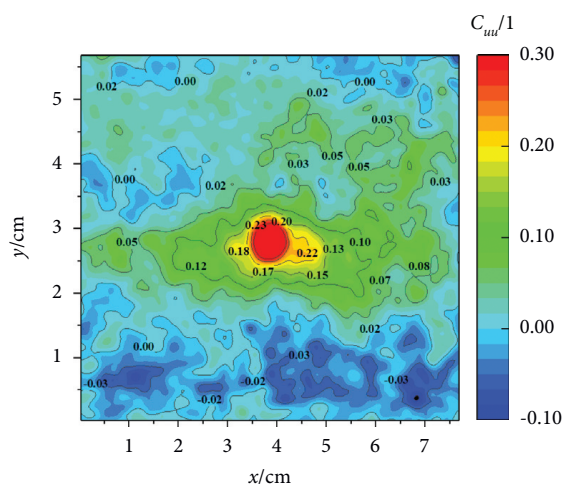

(b)

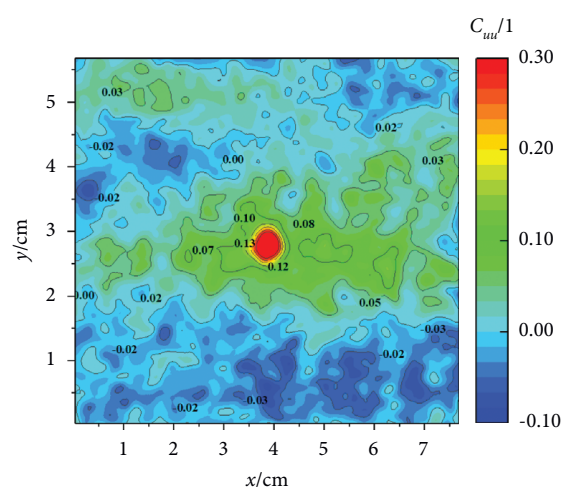

(c)

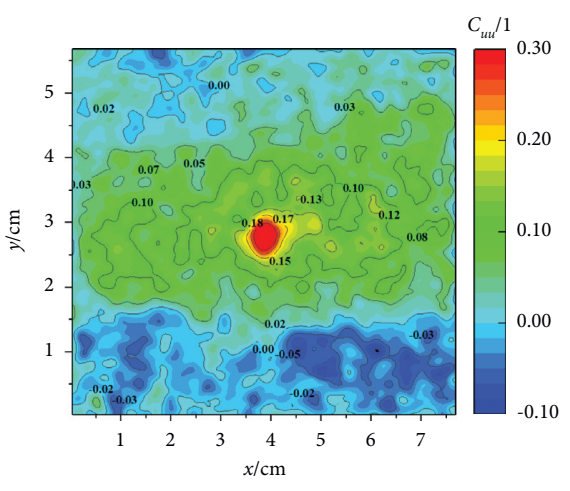

(d)

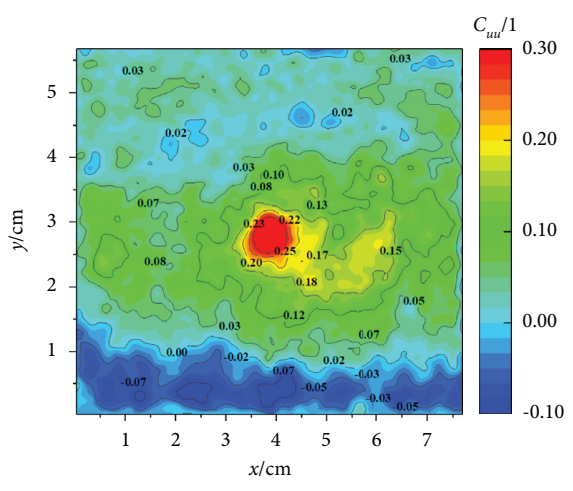

(e)

Figure 7: The distribution of $C_{u u}$ in different working conditions. (a) H25-1, (b) H25-1.2, (c) H25-1.5 (D252), (d) D251, and (e) D253.

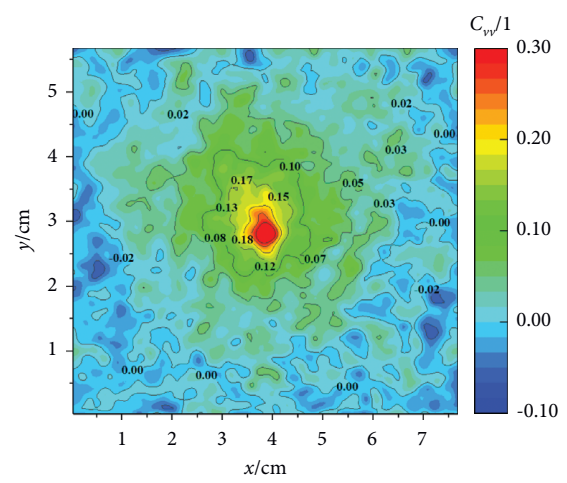

(a)

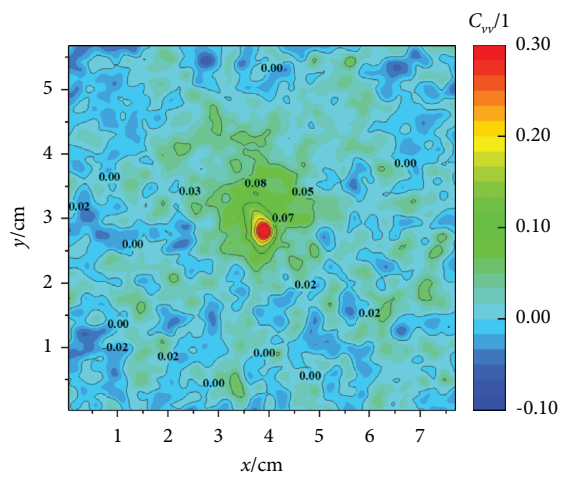

(b)

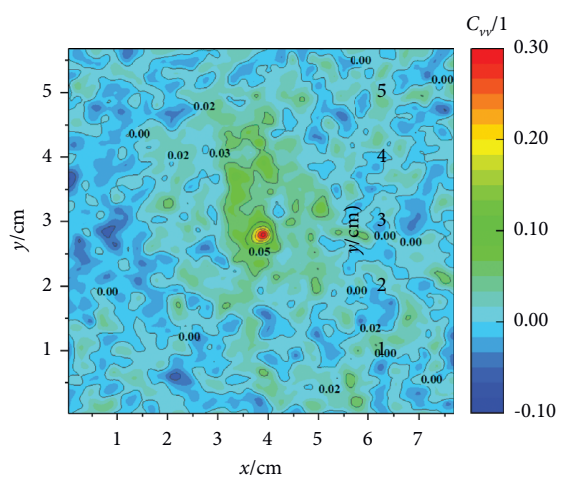

(c)

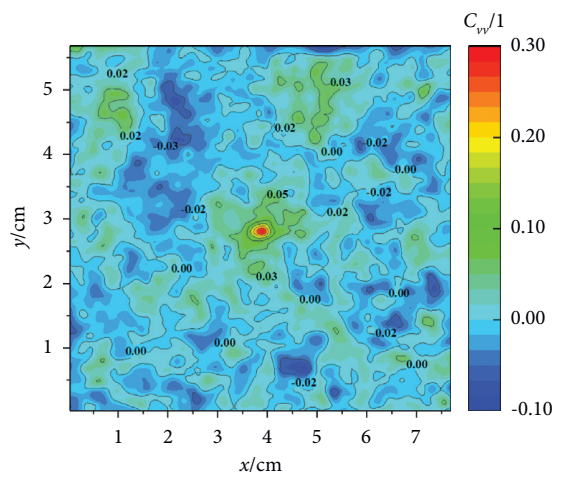

(d)

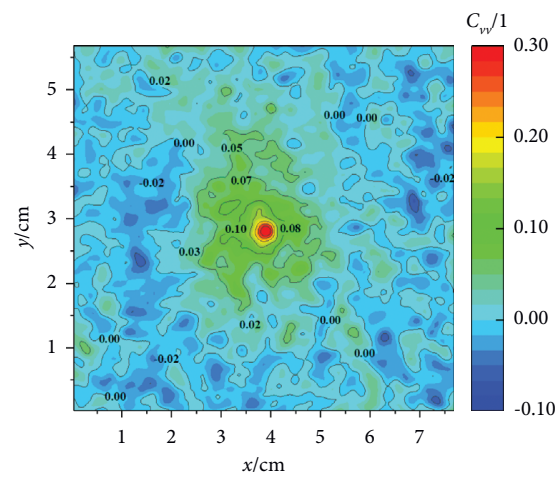

(e)

Figure 8: The distribution of $C_{v v}$ in different working conditions. (a) H25-1, (b) H25-1.2, (c) H25-1.5 (D252), (d) D251, and (e) D253. 
TABLE 3: The value of $\zeta_{u u}$ and $\zeta_{v v}$ in different working conditions.

\begin{tabular}{lcccccccccc}
\hline Correlation coefficient $r$ & \multicolumn{3}{c}{$\zeta_{u u}$} \\
& $\mathrm{H} 25-1$ & $\mathrm{H} 25-1.2$ & $\mathrm{H} 25-1.5(\mathrm{D} 252)$ & $\mathrm{D} 251$ & $\mathrm{D} 253$ & $\mathrm{H} 25-1$ & $\mathrm{H} 25-1.2$ & $\mathrm{H} 25-1.5(\mathrm{D} 252)$ & $\mathrm{D} 251$ & $\mathrm{D} 253$ \\
\hline$<-0.14$ & 0.000 & 0.000 & 0.000 & 0.000 & 0.000 & 0.000 & 0.000 & 0.000 & 0.000 & 0.000 \\
$-0.14 \sim-0.1$ & 0.000 & 0.001 & 0.001 & 0.002 & 0.012 & 0.000 & 0.000 & 0.000 & 0.000 & 0.000 \\
$-0.1 \sim-0.06$ & 0.012 & 0.027 & 0.037 & 0.031 & 0.055 & 0.006 & 0.004 & 0.008 & 0.018 & 0.008 \\
$-0.06 \sim-0.02$ & 0.145 & 0.139 & 0.203 & 0.127 & 0.077 & 0.115 & 0.137 & 0.174 & 0.226 & 0.184 \\
$-0.02 \sim 0.02$ & 0.325 & 0.326 & 0.352 & 0.225 & 0.170 & 0.397 & 0.502 & 0.506 & 0.499 & 0.490 \\
$0.02 \sim 0.06$ & 0.317 & 0.306 & 0.255 & 0.236 & 0.303 & 0.316 & 0.299 & 0.271 & 0.222 & 0.242 \\
$0.06 \sim 0.1$ & 0.115 & 0.115 & 0.113 & 0.217 & 0.195 & 0.097 & 0.046 & 0.037 & 0.029 & 0.056 \\
$0.1 \sim 0.14$ & 0.051 & 0.046 & 0.029 & 0.119 & 0.104 & 0.037 & 0.007 & 0.003 & 0.003 & 0.012 \\
$0.14 \sim 0.18$ & 0.018 & 0.016 & 0.004 & 0.031 & 0.053 & 0.019 & 0.003 & 0.001 & 0.001 & 0.004 \\
$0.18 \sim 0.22$ & 0.007 & 0.011 & 0.002 & 0.005 & 0.017 & 0.006 & 0.001 & 0.000 & 0.000 & 0.001 \\
$0.22 \sim 0.26$ & 0.003 & 0.004 & 0.001 & 0.002 & 0.004 & 0.003 & 0.000 & 0.000 & 0.000 & 0.001 \\
$0.26 \sim 0.3$ & 0.002 & 0.002 & 0.001 & 0.001 & 0.003 & 0.002 & 0.000 & 0.000 & 0.000 & 0.000 \\
$>0.3$ & 0.006 & 0.007 & 0.003 & 0.003 & 0.007 & 0.002 & 0.001 & 0.000 & 0.000 & 0.001 \\
\hline
\end{tabular}

with the increase of the height of bionic grass, the maximum values of $\zeta_{u u}$ and $\zeta_{v v}$ gradually increased, and with the increase of the spacing of bionic grass laying, the maximum values of $\zeta_{u u}$ and $\zeta_{v v}$ increased at first and then decreased.

3.4.2. Spatial Correlation. The distributions of correlation number $C_{u v}$ and $C_{v u}$ are shown in Figures 9 and 10. The results show that the values of $C_{u v}$ and $C_{v u}$ decrease with increasing distance between analytical points and geometric center points of acquisition window. It shows that the bigger the distance between two points, the weaker the spatial correlation between pulsating velocities. $C_{u v}$ and $C_{v u}$ cloud images have dotted distribution. $C_{u v}$ and $C_{v u}$ near the center form anisotropy. Under the same flow conditions, the values of $C_{u v}$ and $C_{v u}$ decreased with the increase of the height of bionic grass and increased with the laying space.

The $\zeta_{u v}$ and $\zeta_{v u}$ values in different working conditions are shown in Table 4 . Results indicated that $\zeta_{u v}$ and $\zeta_{v u}$ generally increased first and then decreased with $r$ increasing. When $r=0, \zeta_{u v}$ and $\zeta_{v u}$ reach maximum value. Under the same flow conditions, with the increase of the height of bionic grass, the maximum value of $\zeta_{u v}$ first increased and then decreased, and the maximum value of $\zeta_{v u}$ gradually decreased. With the increase of the spacing of bionic grass laying, the maximum value of $\zeta_{u v}$ first decreased and then increased, and the maximum value of $\zeta_{v u}$ first increased and then decreased.

3.5. Turbulence Intensity Analysis of Open Channel Flow after Bionic Grass Protection Section. Flow turbulence will cause additional shear stress and energy consumption. The turbulence intensity is often used to characterize the turbulence characteristics of water flow. The turbulence intensity is RMS value of square sum of all fluctuating velocities in this direction during flow fluctuation,

$$
u^{\prime}=\sqrt{\frac{1}{n} \sum_{i=1}^{n} u_{i}^{2}}
$$

$$
v^{\prime}=\sqrt{\frac{1}{n} \sum_{i=1}^{n} v_{i}^{2}}
$$

$u^{\prime}$ and $\mathrm{v}^{\prime}$ are longitudinal and vertical turbulent intensities, $n$ is sample capacity, and $u$ and $v$ are longitudinal and vertical fluctuating velocities.

3.5.1. Longitudinal Turbulent Intensity. The distributions of turbulent intensity along longitudinal flow after bionic grass protection section in different working conditions are shown in Figure 11. It can be seen that the turbulence intensity near the bottom of the canal decreased with the increasing of the height of bionic grass. Compared with the working conditions with grass height of $5 \mathrm{~cm}$ and $7.5 \mathrm{~cm}$, it is found that the longitudinal turbulence intensity of most sections of the latter is obviously lower than that of the former. With the increase of the arrangement distance of bionic grass, the turbulence intensity increased gradually especially near the bottom of the canal.

Figure 12 shows the vertical distribution of longitudinal turbulence intensity after bionic grass protection section in different working conditions $(x=2 \mathrm{~cm})$. When the arrangement density of bionic grass changes, the change rule of longitudinal turbulence intensity is similar. The curve with smaller density is more gentle; that is, the longitudinal turbulence intensity changes in the vertical section faster. The smaller the arrangement density, the lower the extreme point of longitudinal turbulence intensity, which is caused by the different lodging height of bionic grass under different working conditions. 


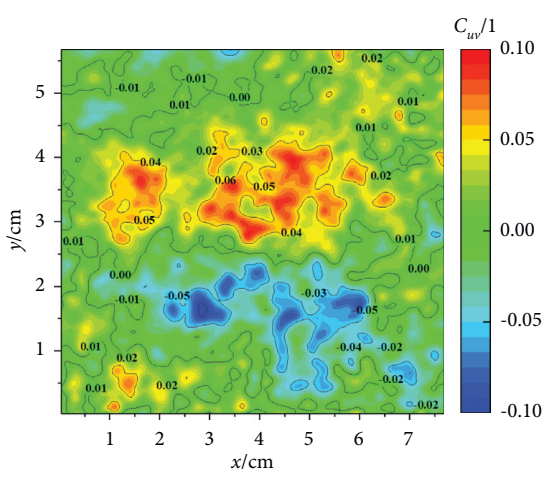

(a)

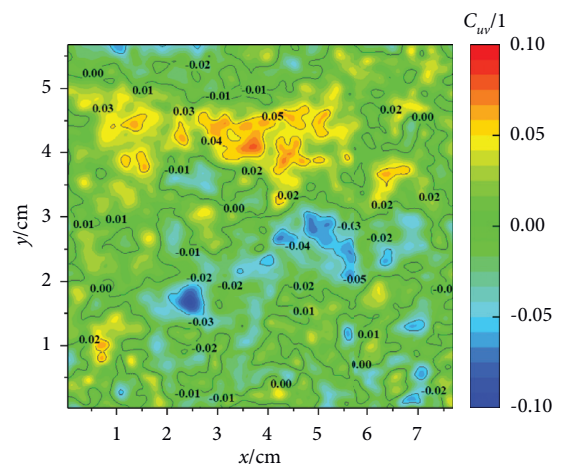

(b)

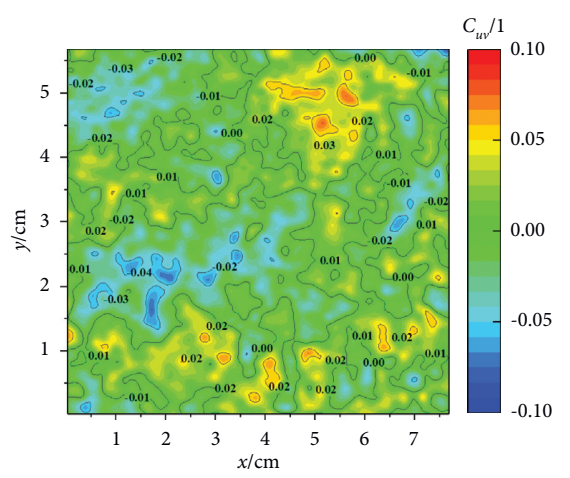

(c)

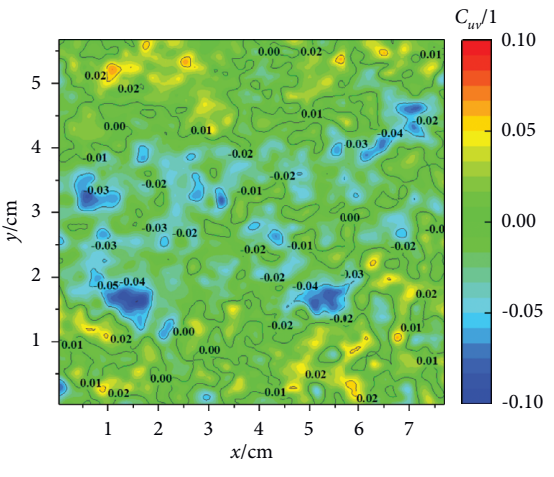

(d)

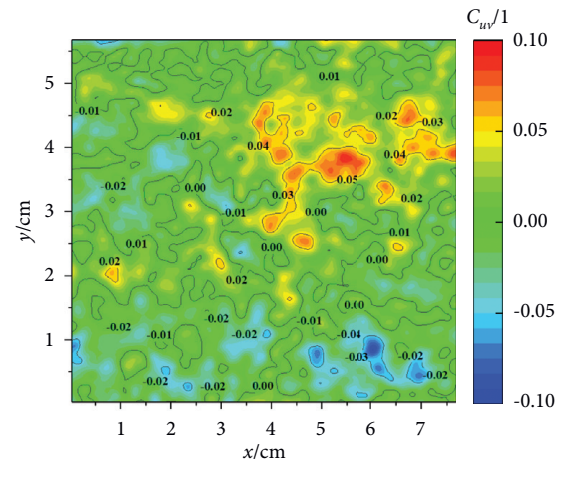

(e)

Figure 9: The distribution of $C_{v u}$ in different working conditions. (a) H25-1, (b) H25-1.2, (c) H25-1.5 (D252), (d) D251, and (e) D253.

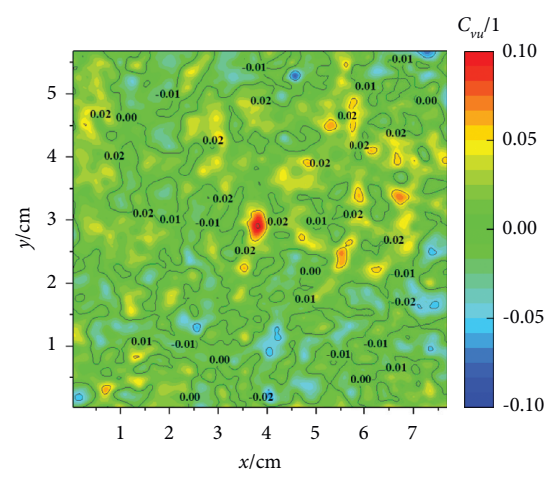

(a)

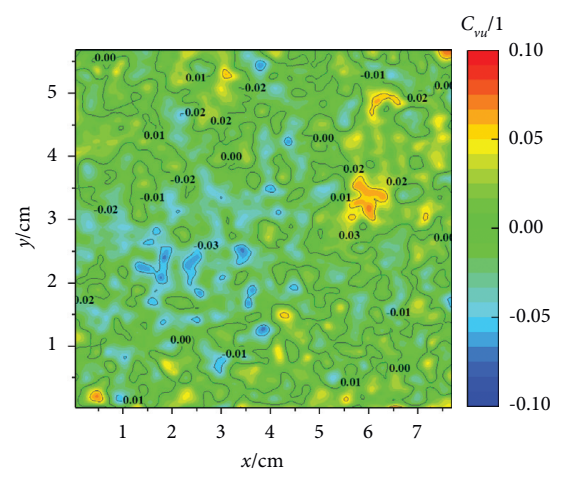

(b)

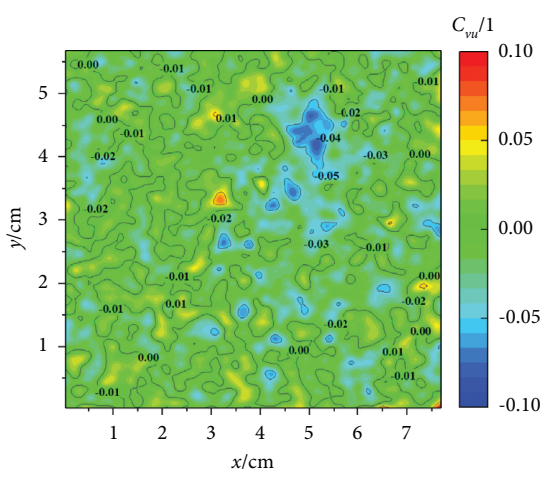

(c)

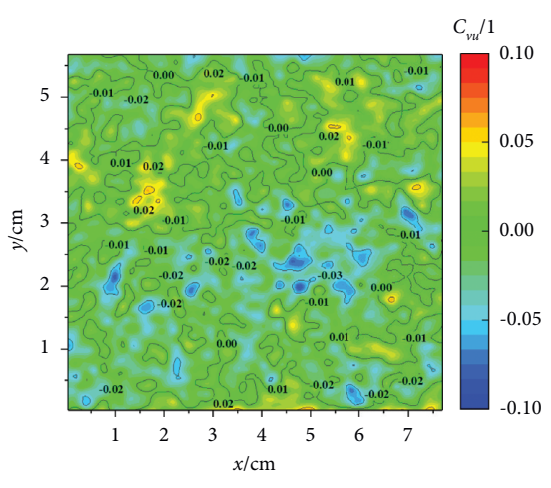

(d)

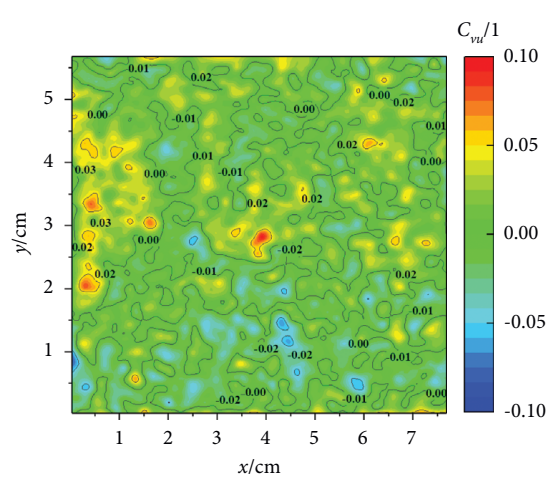

(e)

Figure 10: The distribution of $C_{v u}$ in different working conditions. (a) H25-1, (b) H25-1.2, (c) H25-1.5 (D252), (d) D251, and (e) D253. 
TABLE 4: The value of $\zeta_{u v}$ and $\zeta_{v u}$ in different working conditions.

\begin{tabular}{lcccccccccc}
\hline Correlation coefficient $r$ & \multicolumn{3}{c}{$\zeta_{u v}$} & \multicolumn{4}{c}{$\zeta_{v u}$} \\
& $\mathrm{H} 25-1$ & $\mathrm{H} 25-1.2$ & $\mathrm{H} 25-1.5(\mathrm{D} 252)$ & $\mathrm{D} 251$ & $\mathrm{D} 253$ & $\mathrm{H} 25-1$ & $\mathrm{H} 25-1.2$ & $\mathrm{H} 25-1.5(\mathrm{D} 252)$ & $\mathrm{D} 251$ & $\mathrm{D} 253$ \\
\hline$<-0.1$ & 0.001 & 0.000 & 0.000 & 0.001 & 0.000 & 0.000 & 0.000 & 0.001 & 0.001 & 0.000 \\
$-0.1 \sim-0.08$ & 0.007 & 0.002 & 0.002 & 0.007 & 0.001 & 0.001 & 0.002 & 0.004 & 0.005 & 0.001 \\
$-0.08 \sim-0.06$ & 0.028 & 0.015 & 0.017 & 0.033 & 0.009 & 0.006 & 0.017 & 0.026 & 0.026 & 0.008 \\
$-0.06 \sim-0.04$ & 0.066 & 0.055 & 0.074 & 0.096 & 0.045 & 0.034 & 0.072 & 0.089 & 0.091 & 0.043 \\
$-0.04 \sim-0.02$ & 0.129 & 0.144 & 0.162 & 0.200 & 0.145 & 0.118 & 0.186 & 0.201 & 0.197 & 0.135 \\
$-0.02 \sim 0$ & 0.201 & 0.241 & 0.246 & 0.267 & 0.269 & 0.246 & 0.282 & 0.281 & 0.276 & 0.250 \\
$0 \sim 0.02$ & 0.225 & 0.259 & 0.243 & 0.224 & 0.259 & 0.306 & 0.255 & 0.240 & 0.237 & 0.279 \\
$0.02 \sim 0.04$ & 0.176 & 0.178 & 0.164 & 0.121 & 0.164 & 0.204 & 0.133 & 0.118 & 0.121 & 0.186 \\
$0.04 \sim 0.06$ & 0.104 & 0.084 & 0.073 & 0.041 & 0.076 & 0.070 & 0.044 & 0.034 & 0.038 & 0.078 \\
$0.06 \sim 0.08$ & 0.046 & 0.020 & 0.017 & 0.009 & 0.026 & 0.013 & 0.009 & 0.006 & 0.007 & 0.017 \\
$0.08 \sim 0.1$ & 0.014 & 0.002 & 0.002 & 0.001 & 0.006 & 0.002 & 0.001 & 0.001 & 0.001 & 0.002 \\
$0.1 \sim 0.12$ & 0.002 & 0.000 & 0.000 & 0.000 & 0.000 & 0.000 & 0.000 & 0.000 & 0.000 & 0.000 \\
$>0.12$ & 0.000 & 0.000 & 0.000 & 0.000 & 0.000 & 0.000 & 0.000 & 0.000 & 0.000 & 0.000 \\
\hline
\end{tabular}

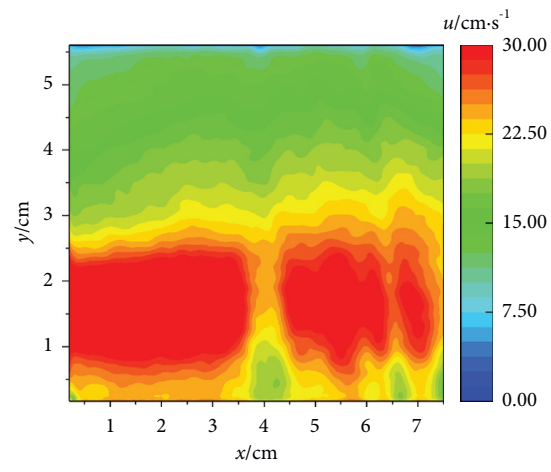

(a)

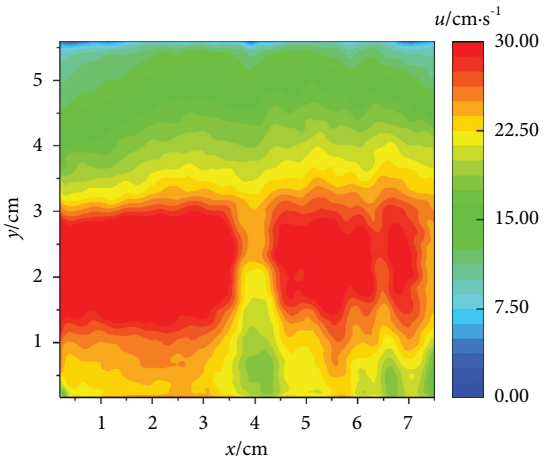

(b)

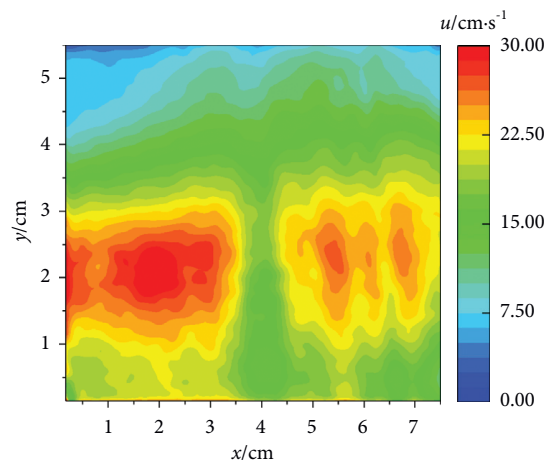

(c)

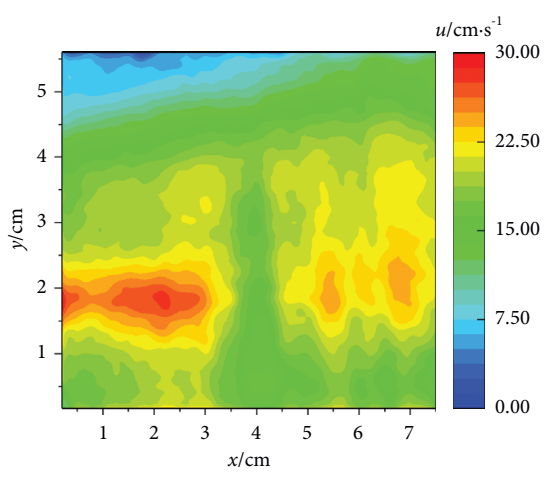

(d)

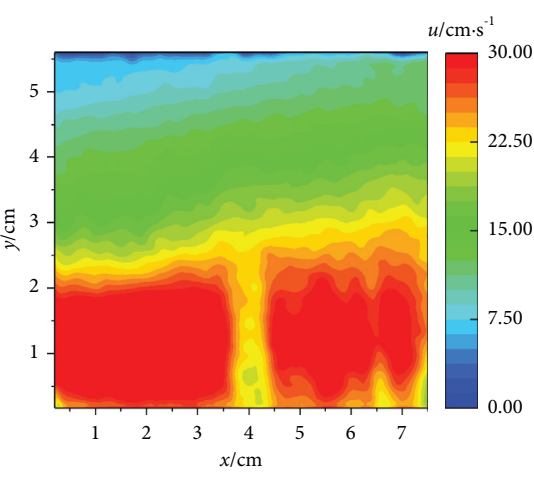

(e)

FIgURE 11: The distribution of the lateral turbulent intensities in different working conditions. (a) H25-1, (b) H25-1.2, (c) H25-1.5 (D252), (d) D251, and (e) D253.

3.5.2. Vertical Turbulent Intensity. It can be seen from Figure 13 that the vertical turbulence intensity near the bottom of the channel is larger. With the increase of grass height, the vertical turbulence intensity near the bottom of the channel becomes smaller. The weakening effect of bionic grass on the turbulence intensity is obviously enhanced when the grass height increases $1.5 \mathrm{~cm}$. When the height of bionic grass increases to a certain value, it will cause the change of turbulence intensity. The vertical turbulence intensity distribution of the flow after the bionic grass protection section in different laying density shows a " $V$ " distribution near the bottom of the channel, while the longitudinal distribution of the upper part is uniform.

Figure 14 is the vertical distribution of vertical turbulent intensity after bionic grass protection section in different working conditions $(x=2 \mathrm{~cm})$. It can be seen from Figure 14 that the curve of the vertical turbulence intensity of the flow behind the bionic grass protection section roughly coincides when the grass height changes little. The smaller change of the grass height is not enough to change the effect of the 


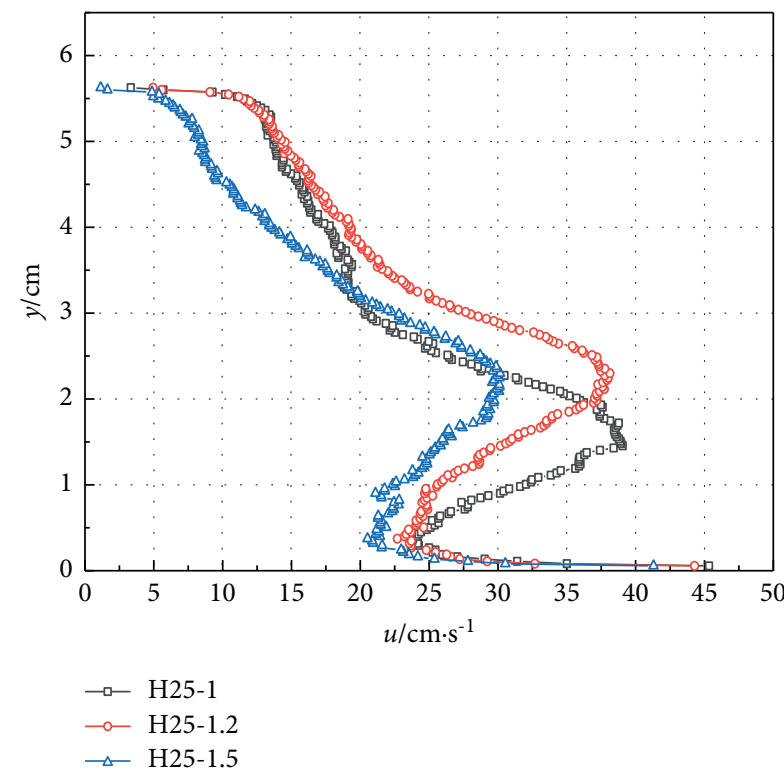

(a)

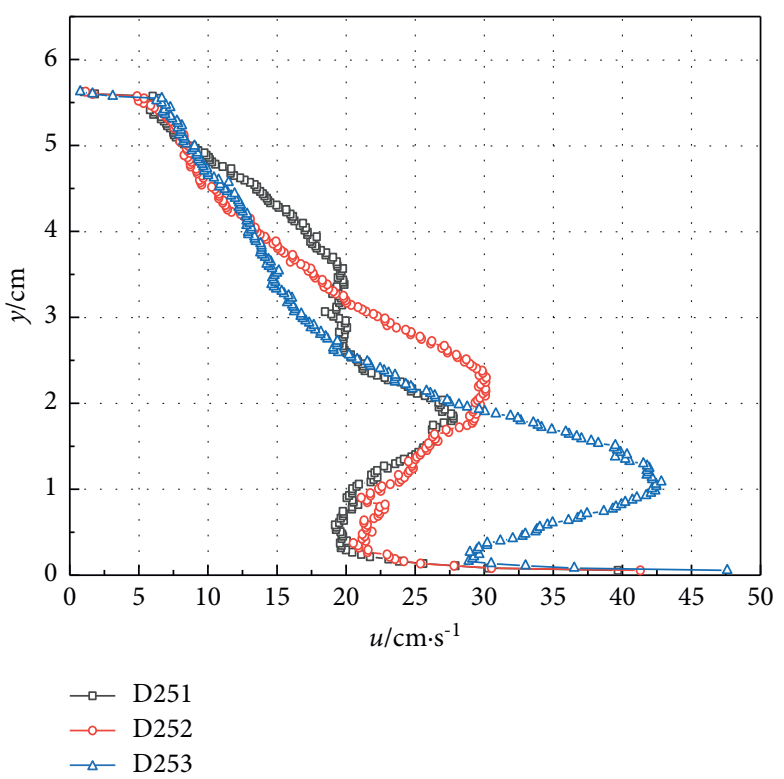

(b)

Figure 12: The vertical distribution of the lateral turbulent intensities in different working conditions $(x=2 \mathrm{~cm})$.

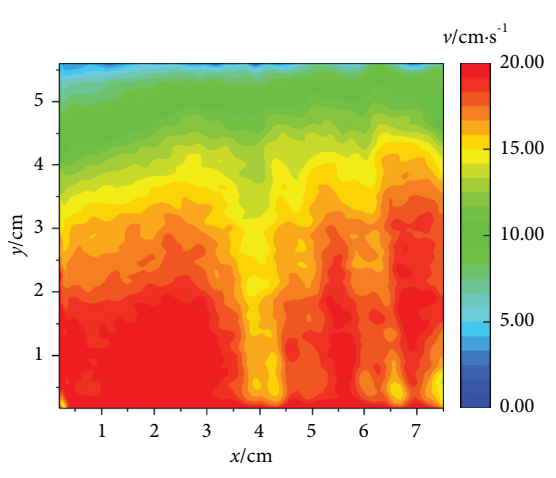

(a)

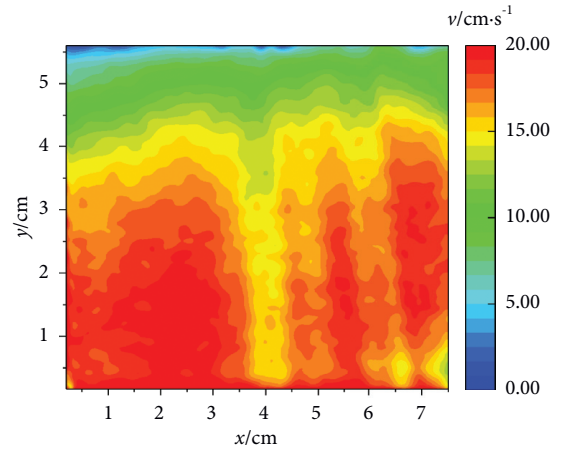

(b)

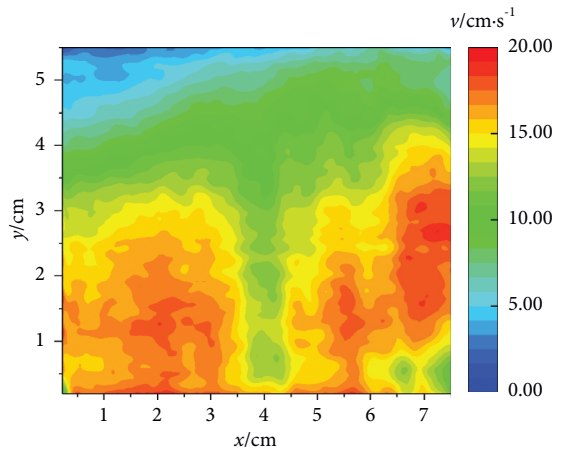

(c)

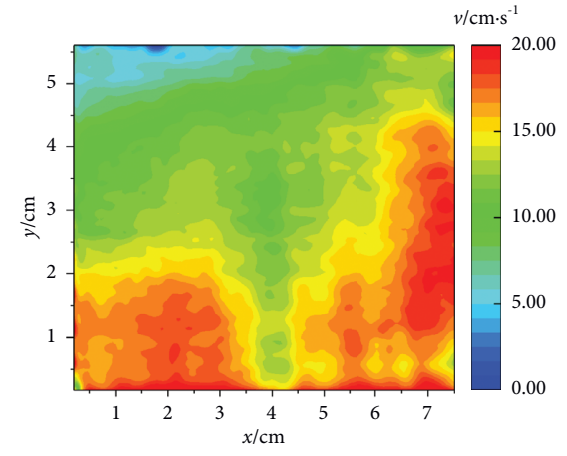

(d)

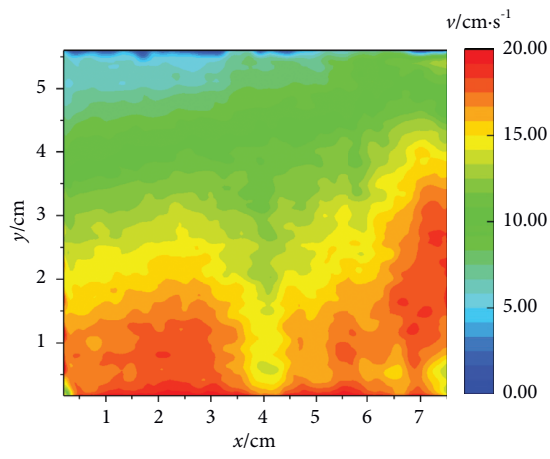

(e)

FIGURE 13: The distribution of the vertical turbulent intensities in different working conditions. (a) H25-1, (b) H25-1.2, (c) H25-1.5 (D252), (d) D251, and (e) D253.

bionic grass on the weakening of the flow turbulence intensity. The laying density of bionic grass has little effect on the vertical turbulence intensity.
3.6. Analysis of Reynolds Stress in Open Channel Flow after Bionic Grass Protection Section. In uniform turbulence, the turbulent shear stress $\tau$ follows the following formula: 


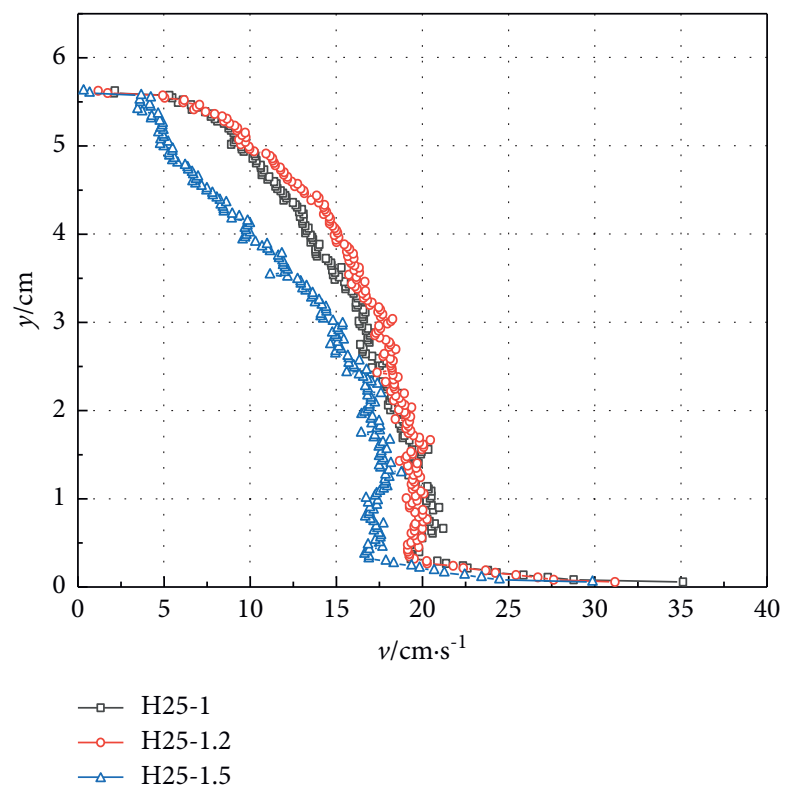

(a)

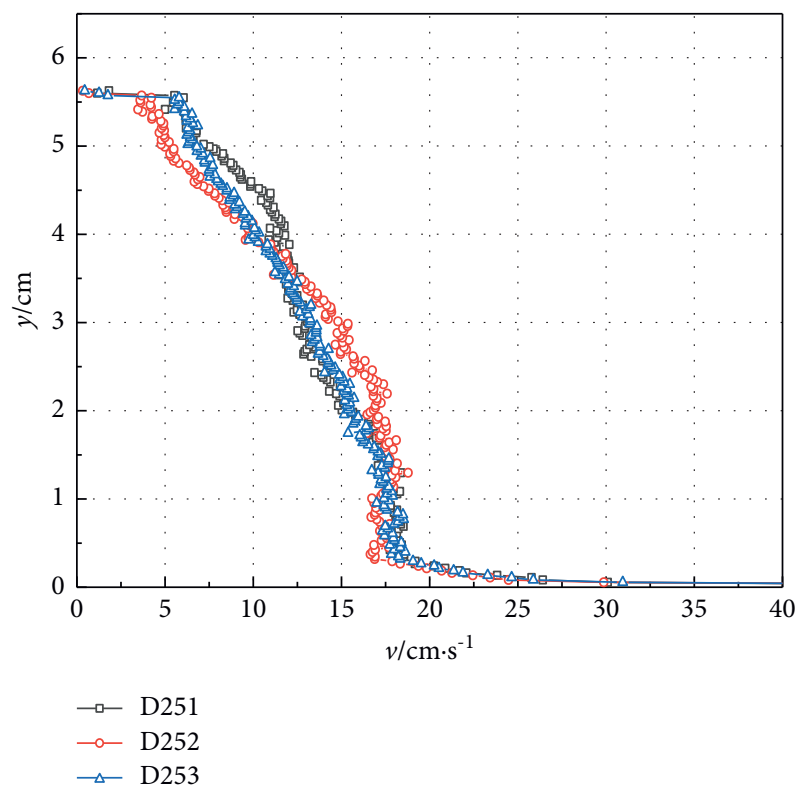

(b)

FIgURE 14: The vertical distribution of the vertical turbulent intensities in different working conditions.

$$
\frac{\tau}{\rho}=-\overline{u v}+v \frac{\partial U}{\partial y}=u_{*}^{2}(1-\eta) .
$$

In the actual process, the velocity gradient is very small, so $v(\partial U / \partial y)$ can be ignored; then.

$$
-\overline{u v}=u_{*}^{2}(1-\eta)
$$

$-\overline{u v}$ is Reynolds stress $\tau_{\operatorname{Re}}$ and $\rho$ is density of water.

It can be seen from Figure 15 that the Reynolds stress along water depth shows a trend of increase firstly and then decrease; even some fluids have negative Reynolds stresses. By comparing the Reynolds stress of the water flow behind the protection section of bionic grass under different grass heights, it can be found that the Reynolds stress near the channel bottom decreases with the increase of grass height. The decrease of Reynolds stress is accompanied by the weakening of momentum exchange. The Reynolds stress near the water surface first increases and then decreases, which is affected by the lodging degree of bionic grass. When the lodging of bionic grass is large, the distribution of Reynolds stress can be seen obviously. At the same time, the distribution of Reynolds stress increases first, then decreases, and then increases with the increase of water depth. The distribution of this alternating transformation is mainly attributed to the disturbance of bionic grass on water flow. For the different laying density, with the decrease of the laying density of bionic grass, the forward Reynolds stress region of the flow behind the protective section of bionic grass expands. On the other hand, the negative Reynolds stress distribution area narrows and shows a decreasing trend. The longitudinal distribution of Reynolds stress near the bottom of the canal is gradually uniform and zonal.

The vertical distributions of Reynolds stress after bionic grass protection section in different working conditions $(x=2 \mathrm{~cm})$ are shown in Figure 16. It can be found that on the side where the Reynolds stress is positive, the flow Reynolds stress extreme value is the highest when the grass height is $6 \mathrm{~cm}$. On the side where the Reynolds stress is negative, the maximum Reynolds stress of the flow after the bionic grass protection section with the grass height is $5 \mathrm{~cm}$. Under the condition of the same flow velocity, when the height of bionic grass is $7.5 \mathrm{~cm}$, the variation range of Reynolds stress along the water depth is the smallest and the most stable. It indicates that the height of bionic grass determines the distribution of Reynolds stress. Meanwhile, different laying density has little effect on the Reynolds stress.

\subsection{Analysis of Turbulent Energy in Open Channel Flow after} Bionic Grass Protection Segment. The turbulent kinetic energy is based on the Reynolds time mean point of view, comprehensively considering the pulsation in two directions, and the time-average is used to express the pulsating force of the flow. Turbulent kinetic energy shows the energy of pulsating water masses in turbulent flow, which is expressed in $E$.

$$
E=\frac{\left(u_{I}^{\prime 2}+v_{I}^{\prime 2}\right)}{2} .
$$

$u_{i}^{\prime}$ and $v_{i}^{\prime}$ respectively indicate longitudinal and vertical fluctuating velocity intensities of currents, respectively.

It can be seen from Figure 17 that the maximum turbulent kinetic energy appears near the bottom of the channel or the lodging position of bionic grass. The explanation is that the momentum exchange of flow particles is intense at these locations. The higher the bionic grass is, the sparser the distribution band of the maximum turbulent kinetic energy is. The turbulent energy near the water surface becomes 


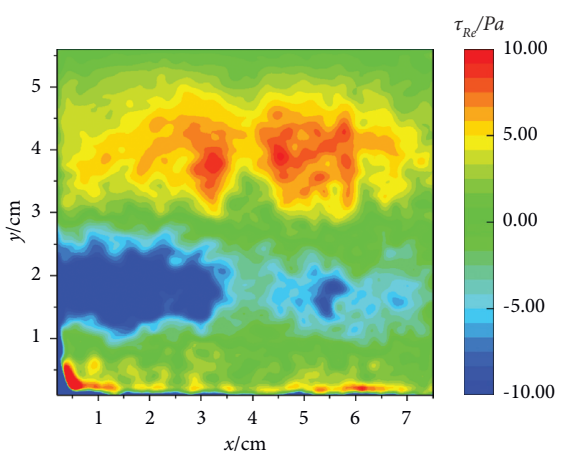

(a)

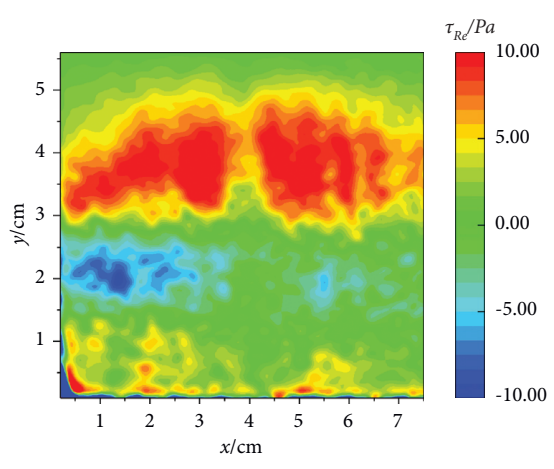

(b)

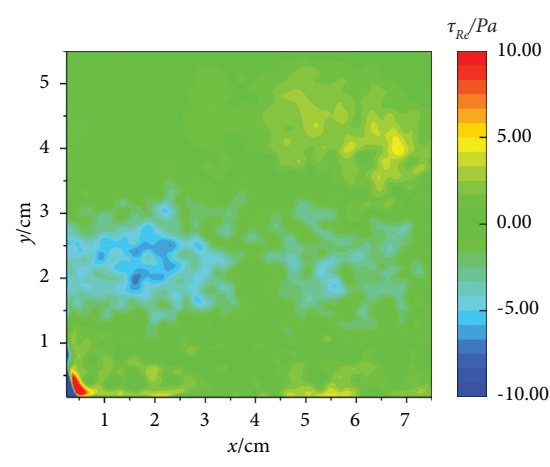

(c)

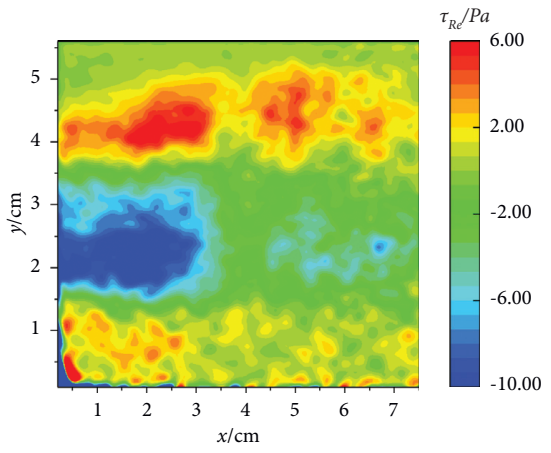

(d)

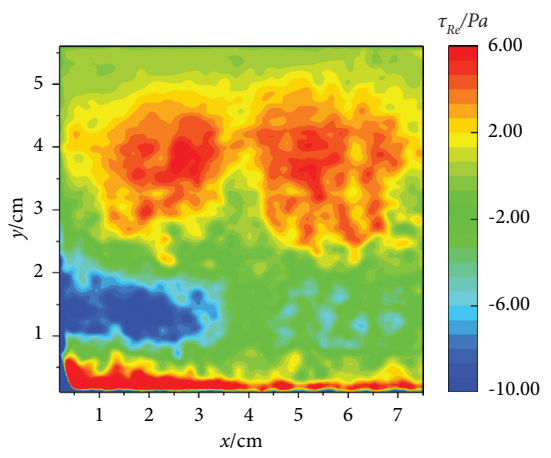

(e)

Figure 15: The distribution of Reynolds stress in different working conditions. (a) H25-1, (b) H25-1.2, (c) H25-1.5 (D252), (d) D251, and (e) D253.

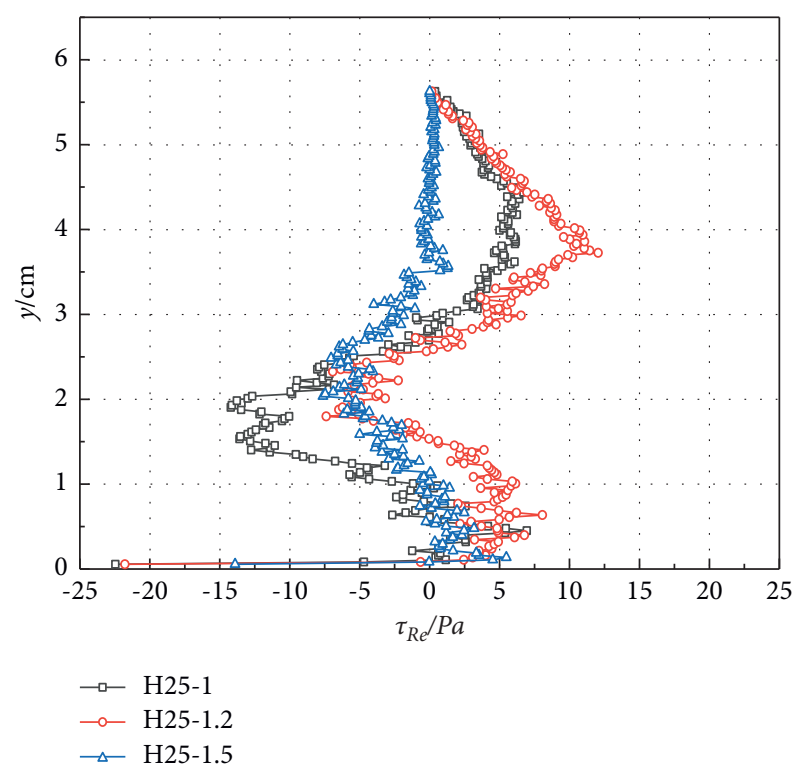

(a)

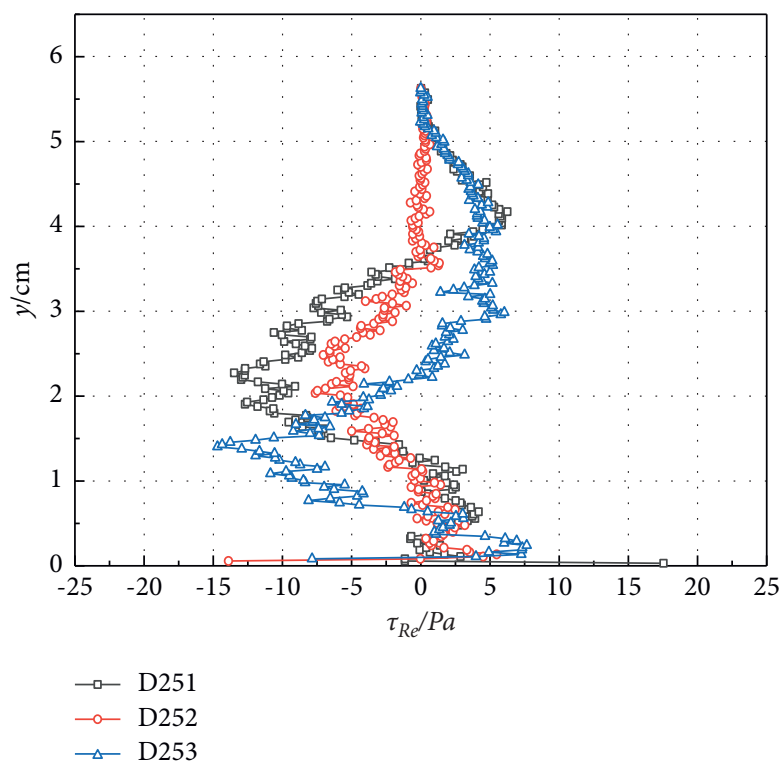

(b)

FIGURE 16: The vertical distribution of Reynolds stress in different working conditions $(x=2 \mathrm{~cm})$.

smaller with the decrease of the arrangement density of bionic grass. Figure 18 shows vertical distribution of turbulent energy of water flow after bionic grass protection section under different working conditions $(x=2 \mathrm{~cm})$. The test results show that the turbulent energy decreases with the increase of bionic grass height. However, the turbulent energy near the bottom of the channel increases with the increase of grass height. At the same time, with the increase 


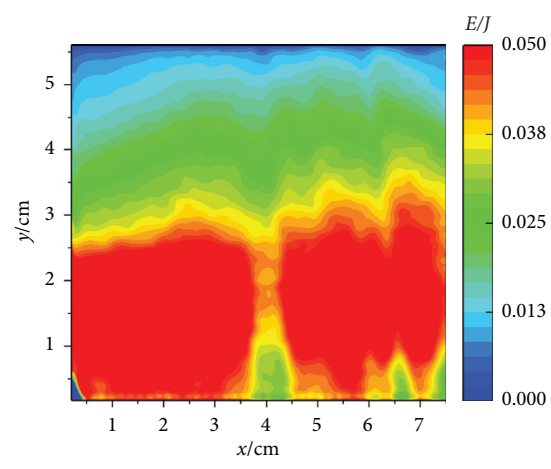

(a)

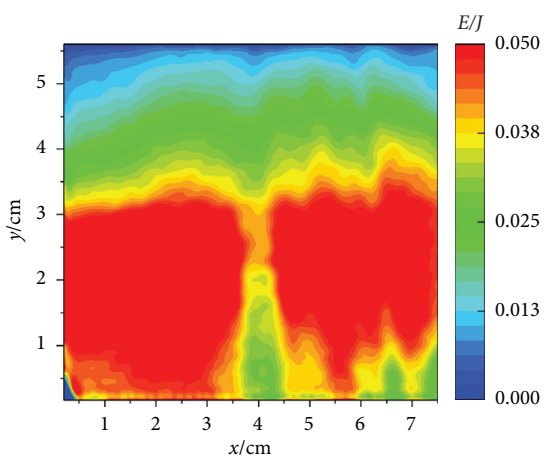

(b)

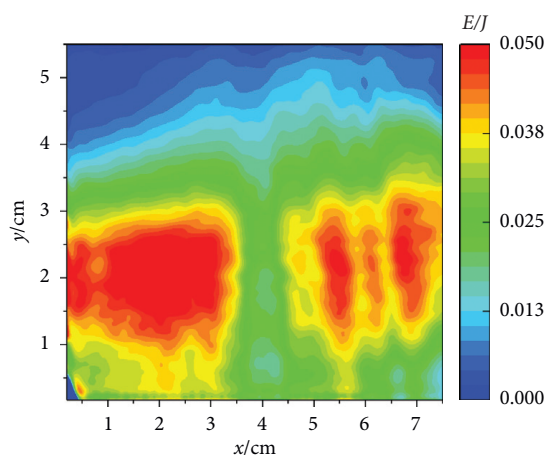

(c)

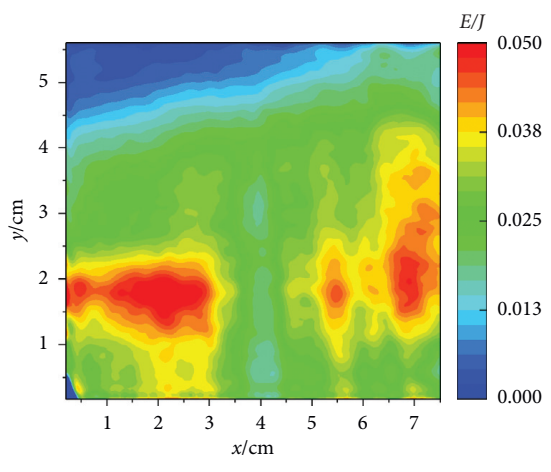

(d)

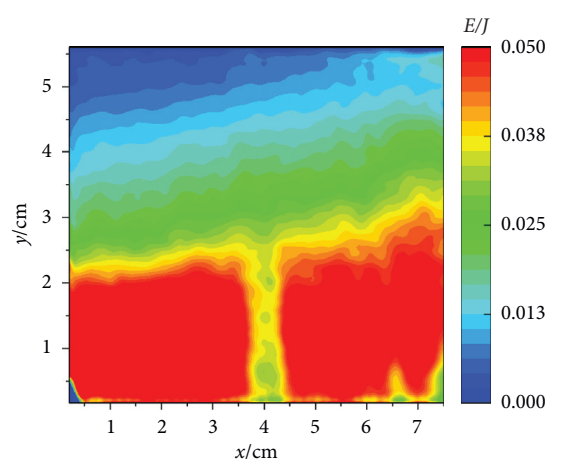

(e)

FIGURE 17: The distribution of the kinetic energy in different working conditions. (a) H25-1, (b) H25-1.2, (c) H25-1.5 (D252), (d) D251, and (e) D253.

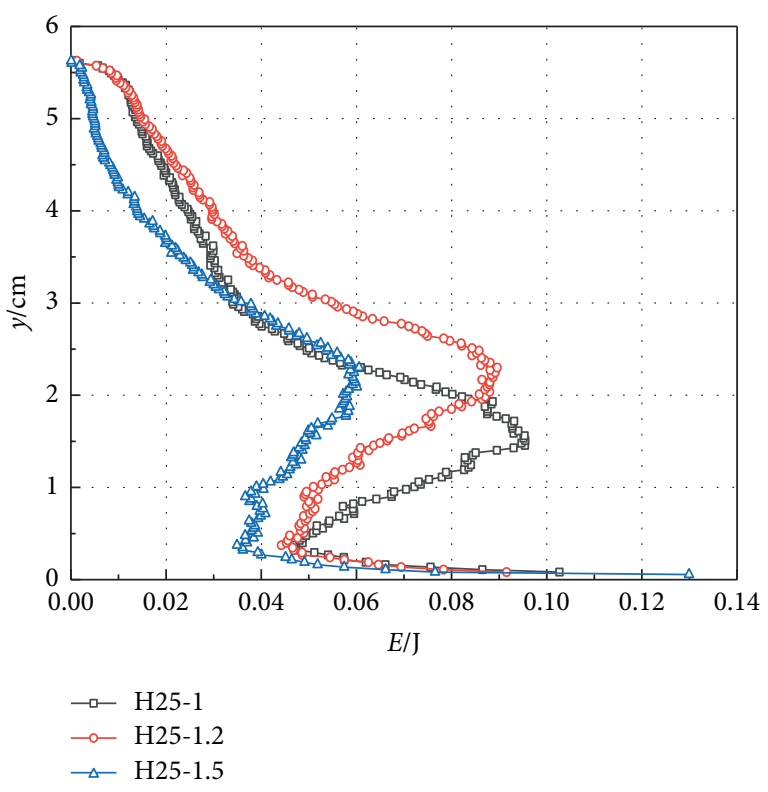

(a)

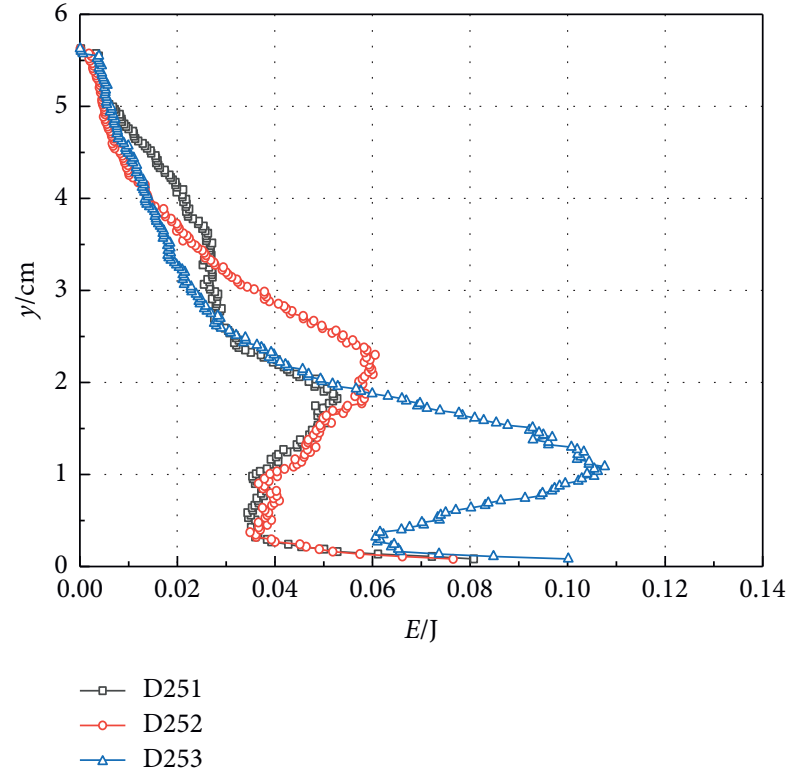

(b)

FIGURE 18: The vertical distribution of the kinetic energy in different working conditions $(x=2 \mathrm{~cm})$.

of the spacing between bionic grasses, the maximum position of turbulent energy gradually approached to the bottom of the canal.
In addition, because the bionic grass is a flexible material, the swing range is large in the test process, the bionic grass mat will produce local turbulence, which will lead to the 
peak value of turbulent kinetic energy increasing, and the range of peak value change expands. After that, the turbulent kinetic energy decreases rapidly. Due to the effect of Carmen vortex, the second peak value will appear after the decrease of turbulent kinetic energy, which will increase again. Therefore, it can be seen that the turbulent kinetic energy decreases significantly near $x=4 \mathrm{~cm}$.

\section{Conclusion}

In this paper, through the physical model test of bionic grass, the flow velocity structure and turbulence characteristics of the open channel behind the protective section of bionic grass are analyzed.

(1) With the increase of the grass height, the time-average velocity near the lodging height of the bionic grass decreases. The maximum mean longitudinal velocity in the middle of the channel increases with the increase of the spacing of bionic grass.

(2) With the increase of grass height, the kurtosis of the normal distribution of vertical pulsation frequency increases gradually. With the increase of the spacing of bionic grass laying, the maximum value of probability distribution increases firstly and then decreases. Under the condition of D252 arrangement density, the symmetry of the probability distribution curve of longitudinal fluctuating velocity is better, and the trend of normal distribution is flatter.

(3) The maximum correlation coefficient of $C_{u u}$ and $C_{v v}$ is about $r=0.3$, and there is a nonlinear relationship between $r$ and the proportion of $C_{u u}$ and $C_{v v}$. The correlation coefficient accounts for the largest proportion when the relative coefficient is about $r=0.02$. The maximum correlation coefficient between $C_{u v}$ and $C_{v u}$ is about $r=0.12$. There is also a nonlinear relationship between the proportion of $r$ and $C_{u v}$ and $C_{v u}$. The correlation coefficient accounts for the largest proportion when the correlation coefficient is about $r=0$.

(4) Under the same flow conditions, the higher the biomimetic grass, the smaller the longitudinal turbulence intensity of the water flow after the biomimetic grass protection section. With the decrease of the density of the biomimetic grass laying, the longitudinal turbulence intensity increases, which is close to the vertical distribution of the turbulence intensity of the direct inflow in the case of no grass. This indicates that the height and laying density of the biomimetic grass are important parameters affecting the turbulence intensity of the open channel flow. The vertical turbulence intensity distribution is approximately exponential distribution. The closer it is to the bottom of the channel, the greater is the vertical turbulence intensity. The higher the height of biomimetic grass, the smaller the vertical turbulence intensity of water flow. However, the influence of the density of biomimetic grass laying on the distribution of vertical turbulence intensity is not big.

(5) The Reynolds stress of flow increases first, then decreases, and then increases along the water depth. When the height of the biomimetic grass is higher, the Reynolds stress oscillates along the water depth with the smallest amplitude and the most stable.

(6) The turbulence energy decreases with the increase of the height of the biomimetic grass. The spacing between bionic grass laying is larger. The greater the turbulence energy in the area near the canal bottom, the more intense the momentum exchange.

\section{Data Availability}

All data and models used during the study appear in the submitted article. All data and models included in this study are available upon request by contact with the corresponding author.

\section{Conflicts of Interest}

The authors declare that they have no conflicts of interest.

\section{Acknowledgments}

This study was supported by the National Natural Science Foundation of China under grant no. 51709025, the Key Laboratory of Port and Waterway Sediment Engineering Transportation Industry of Nanjing Hydraulic Research Institute (Yk220001-6), Open Research Fund of Key Laboratory of Failure Mechanism and Safety Control Techniques of Earth-Rock Dam of the Ministry of Water Resources (YK321003), and the basic science and advanced technology research projects of Chongqing Science and Technology Committee (cstc2018jcyjAX0391 and cstc2018jcyjAX0084).

\section{References}

[1] J. Li, Z. Hou, and P. Tian, "Bionic grass protection technology for submarine pipelines under the threat of huge wave erosion," Coastal Engineering, vol. 36, no. 4, pp. 37-43, 2017.

[2] L. Zhuang, J. Yan, and F. Fan, "Study of artificial seaweeds in hanging segment of submarine pipelines in Maoming single point mooring dock for $30 \times 104 \mathrm{t}$ oil unloading," Ocean Engineering, vol. 28, no. 2, pp. 76-81, 2010.

[3] Q. Meng and Y. Wu, "Experimental study on wave absorbing characteristics of bionic grass in coastal waters," Journal of Water Resources and Architectural Engineering, vol. 4, pp. 185-190, 2014.

[4] F. López and M. H. García, "Mean flow and turbulence structure of open-channel flow through non-emergent vegetation," Journal of Hydraulic Engineering, vol. 127, no. 5, pp. 392-402, 2015.

[5] C. Wilson, P. D. Bates, and T. Stoesser, "Open channel flow through types of flexible submerged vegetation," in Proceedings of Assembly of the European Geophysical Society, Nice, France, May 2001. 
[6] F. Wu, W. Wang, and S. Jiang, "Hydrodynamics development in vegetated open channel," Advances in Water Science, vol. 18, no. 3, pp. 456-461, 2007.

[7] F. Wu, S. Jiang, and L. Xing, "Measurement of flow field with submerged rigid vegetation by PIV," Engineering Journal of Wuhan University, vol. 42, no. 5, pp. 587-591, 2009.

[8] C. Wang and C. Wang, "Turbulent characteristics in openchannel flow with emergent and submerged macrophytes," Advances in Water Science, vol. 21, no. 6, pp. 816-822, 2010.

[9] H. Wenxin, J. Han, and Y. Zeng, "Experimental study on hydraulic behaviors of steady uniform flow in open channel with submerged flexible vegetation," Journal of Hydraulic Engineering, vol. 40, no. 7, pp. 791-797, 2009.

[10] Y. Song, H. Jing, and K. Zhang, "Experimental study on characteristics of open channel flows with submerged rigid vegetation," Journal of Hydroelectric Engineering, vol. 38, no. 4 , pp. 23-34, 2019. 